\title{
NTIC E INNOVACIÓN DOCENTE: JUEGOS EN SOPORTE DIGITAL PARA COMPLEMENTAR EL APRENDIZAJE DE LA PALEOGRAFÍA
}

\section{NTIC AND EDUCATIONAL INNOVATION: GAMES WITH DIGITAL SUPPORT TO COMPLEMENT THE LEARNING OF PALAEOGRAPHY}

Leonor Zozaya-Montes

IATEXT, Universidad de Las Palmas de Gran Canaria (España) - CHSC, Universidade de Coimbra (Portugal)

leonor.zozaya@ulpgc.es

\begin{abstract}
Resumen
Este artículo propone usar juegos como complemento para reforzar conocimientos previamente adquiridos de Paleografía de lectura. Tras ofrecer una definición de juego, y conjeturar sobre sus límites subjetivos, el artículo reúne teorías históricas que recalcan los beneficios de introducirlo en la docencia. También pincela avances dados en Humanidades Digitales y en Paleografía Digital. Además, trata corrientes pedagógicas de innovación educativa que introducen juegos y NTIC (Nuevas Tecnologías de la Información y la Comunicación) para enseñar. Repasa métodos de docencia de Paleografía, tradicionales y modernos, incluyendo cursos interactivos en línea. Se centra en los escasos juegos de paleografía existentes, en la Paleoteca y en otros proyectos, como el borrador de Santos. Concluye reflexionando sobre la escasez de los denominados juegos de Paleografía, cuando el contexto docente propiciaría incluirlos.
\end{abstract}

Palabras clave: Paleografía. Docencia lúdica. NTIC. Interactivo. Juegos educativos. 


\section{Abstract}

This article proposes to include games as complement to reinforce previously acquired knowledge of reading palaeography. After offering a definition of game, wondering about its subjective limits, this study gathers theories remarking benefits of introducing games for teaching. It also deals on the progresses made in Digital Humanities and Digital Palaeography. Furthermore, pedagogical theories of educational innovation that use games and NTIC (New Technologies of Information and Communication) to teach are reviewed. Palaeographical methods for teaching, traditional and modern, including online interactive courses are also revised. The analysis focuses on the reduced number of palaeographical games, on the Paleoteca and on other projects, as Santos' sketch. The conclusion reflects about the fact that the so-called palaeography games are still very few, when the educational context is favourable to include them.

Keywords: Palaeography. Ludic Teaching. NTIC. Interactive. Educational Games.

\section{LA DEFINICIÓN DE JUEGO Y SUS LÍMITES SUBJETIVOS}

Existen numerosas definiciones de juego. Aunque algunas sean más populares, no hay unanimidad. Definirlo es una labor difícil, si se tiene en cuenta la complejidad de las manifestaciones del fenómeno lúdico a lo largo de la historia. Así lo evidencia un análisis tanto del origen etimológico de la palabra, como de su uso contemporáneo en varias lenguas (Huizinga, 1980: 28-45).

Huizinga, un historiador de referencia en estas materias, definió el juego como una actividad u ocupación voluntaria ejecutada con ciertos límites fijados de tiempo y espacio, de acuerdo con reglas libremente aceptadas pero herméticas, que se acompaña del sentimiento de tensión y diversión, junto con la conciencia de realizar una actividad diferente a la de la vida ordinaria (Huizinga, 1980: 28).

Comparando con definiciones más simples, cabría tener en cuenta una referencia orientativa, el vocablo juego del Diccionario de la Lengua Española. En su primera acepción menciona la acción que busca el entretenimiento. En su segundo significado precisa que es el "ejercicio recreativo o de competición sometido a reglas, y en el cual se gana o se pierde" (DRAE, 2016). 
Aquí se seguirá esta definición genérica de juego: "una actividad que tiene la intención de entretener, que cuenta con reglas, y que se da en un contexto artificial" (Zozaya-Montes, 2015a). Esta enunciación deja al margen aspectos particulares de ciertos juegos, que limitarían conceptualmente, como ganar o perder algo.

Cabe señalar que en ocasiones es problemático delimitar las fronteras del juego. ¿Cuándo determinados ejercicios o ciertas actividades pueden comenzar a denominarse juegos, o al contrario? Definirlo dependerá de diversas cuestiones subjetivas como las teorías docentes, las connotaciones lingüísticas y la idiosincrasia del lugar cuya institución se responsabilice del hecho, ya sea un juego, o una actividad docente, tal vez de apariencia lúdica. Tales cuestiones volverán a salir a colación posteriormente.

\section{BREVE RECORRIDO HISTÓRICO POR ALGUNAS TEORÍAS SOBRE LOS BENEFICIOS DE INCLUIR EL JUEGO EN EL APRENDIZAJE}

Esta propuesta bien podría haber nacido como fruto de un juego de asociaciones, usando la técnica del binomio fantástico propuesta por Gianni Rodari en su Gramática de la fantasía (1983). Su sistema consistía en elegir dos palabras que no estuviesen relacionadas para asociarlas de forma insólita e imaginativa, haciendo convivir a dos elementos extraños. Así, escogiendo paleografía y juego podríamos haber llegado a esta propuesta. Aunque haya tenido orígenes menos literarios, invita a reivindicar que es necesario que la imaginación tenga un puesto en el proceso educativo (Rodari, 1983).

Jugar ha sido visto como el acto opuesto a cualquier actividad seria (Huizinga, 1980: 5). En esa línea, la enseñanza en la educación universitaria tradicional suele estar relacionada con actitudes serias. Quizás por ello los departamentos universitarios no acostumbran a remarcar las cualidades positivas del juego para reforzar conocimientos de materias tan serias como la paleografía.

Esta propuesta no significa que se pretenda convertir la universidad en un parvulario, en absoluto. Quien escribe estas líneas concuerda con ofrecer la enseñanza "rigurosa, exigente y disciplinada" defendida en el Panfleto Antipedagógico (Moreno Castillo, 2006: 20). Pero eso no está reñido con alternar ese método con breves momentos lúdicos, premiando a modo de incentivo mediante el juego, para aumentar el rendimiento. Estudiar, memorizar y aprender es difícil. Por ello a lo largo de la historia han sido inventados numerosos sistemas para facilitar el aprendizaje, como el del famoso Ars memoriae, o arte de la memoria, con sus complicadas reglas mnemotécnicas para auxiliar a la retentiva. Al respecto, por cierto, opinaba Feijoo que, lejos de lograr su finalidad, sólo servía "para ostentación y juego" (Feijoo, 2014: $355)$. 
En cualquier caso, ambas actividades, juego y aprendizaje, pueden ser compatibles. Así lo reconocía una obra medieval, el Tractatus de Ludo Scacorum, o tratado del juego del ajedrez, que también contiene afirmaciones estrictas, por ejemplo: el ocio es "la sentina de los vicios". Pero a la par es flexible al atribuir a un filósofo virtuoso la invención del ajedrez, gracias al cual "lo serio, disfrazado de juego, ya devuelve las fuerzas al ánimo cansado por los trabajos, y lo remoza" (Vázquez de Parga, 1970: 35-36)1.

Los beneficios del juego han sido señalados por diversos teóricos de forma dispersa y fragmentaria durante las épocas moderna y contemporánea. Los orígenes de los estudios de la teoría del juego se han asociado con nombres de filósofos afamados como Schiller, Spencer o Wundt, quienes vinculaban el origen del juego al arte y a la estética (Elkonin, 1980: 19 y 20).

Schiller, en las Cartas sobre la educación estética del hombre ${ }^{2}$, afirma que "entre todos los estados del hombre, es precisamente el juego, y solo el juego, lo que lo hace completo" (Schiller, 1981: 91). También asevera que el humano "sólo actúa seriamente con lo agradable", lo cual le permite llegar a "la expansión" (Schiller, 1981: 91). Esa última expresión podría referirse a que el juego promueve la expansión del ánimo, preparándolo o predisponiéndolo para recibir conocimiento, ampliándolo.

En el siglo $X X$, varios pedagogos comenzaron a estudiar sistemáticamente teorías sobre el aprendizaje vinculado a la cultura, relacionando principalmente la infancia con los juegos. Entre otros muchos, destacan nombres como Brunner, Elkonin, Piaget, Skynner, Thorndike o Vigotsky (Schunk, 2012).

Desde el año 1938, diversas disciplinas comenzaron a plantearse seriamente las virtudes de los juegos como apoyo a la cultura, cuando Johan Huizinga, entonces profesor en la Universidad de Leiden, publicó la obra Homo Ludens. El prestigioso medievalista exponía las grandes virtudes de los juegos en el desarrollo de la cultura de la humanidad. Subrayaba la importancia suprema del factor lúdico, aventurando que la categoría lúdica había sido una de las más importantes en la evolución de la civilización (Huizinga, 1980: 28).

El juego cuenta con numerosas virtudes; por ejemplo, disciplina los instintos (Caillois, 1961). Si se vincula acertadamente con la docencia, será muy productivo, al permitir practicar los conocimientos adquiridos y, a su vez, motivando, incentivando y despertando la curiosidad. $\mathrm{Si}$, además del juego y la docencia se utilizan las NTIC, supondrá un aliciente más para el alumnado.

\footnotetext{
1 "In quo seria picta iocis nunc animum laboris fessum viribus revocat alias renouat nunc viciorum sentinam tollit ocium", como reza en el original de la Biblioteca Nacional de España (Vit. 25-6).

2 Entiéndase hombre por persona.
} 


\section{TENDENCIAS EXITOSAS: NTIC, JUEGOS EDUCATIVOS Y OTRAS VARIANTES}

En los últimos años han proliferado diversas tendencias docentes que incluyen las Nuevas Tecnologías de la Información y la Comunicación (NTIC) en la docencia, y que se vinculan al aprendizaje mediado por la electrónica (el denominado e-learning). Muchas de esas corrientes valoran el juego como un gran estímulo en la educación, lo cual se ha aplicado a numerosas disciplinas (Crookall, 2010: 898-920). La benignidad docente de los juegos digitales ya ha sido demostrada en diversos campos (Chin et al., 2009: 553-568; Bellotti et al, 2013: 1-11), cuyas ventajas es posible ponderar analíticamente (Freire et al., 2016: 1-29). Los juegos son una herramienta poderosa, por ejemplo, para invitar a descubrir su patrimonio artístico a quienes no están familiarizados con la cultura (Bellotti et al., 2012: 1-27).

Diversas tendencias educativas incluyen acciones lúdicas con intenciones docentes en contextos ajenos al juego. Están dirigidas a diversos públicos -incluyendo el estudiantilentre las que cabría destacar dos, aunque en ocasiones están aunadas. Una rama es la referida a los juegos educativos, del inglés educational games, o a los popularmente conocidos como juegos serios, de Serious Games o SGs (Freire et al., 2016: 1-29; Gloria et al., 2014: 1-15). Otra rama está representada por la denominada gamification (Deterding et al., 2011a: 9-15; Deterding et al., 2011b: 2425-2428). La investigación al respecto ha proliferado enormemente en los últimos años, acompasada con celebraciones de congresos internacionales, junto con ediciones de revistas científicas especializadas, que generalmente se relacionan con tecnología e informática.

Esas corrientes lúdicas también han tenido buena acogida en países hispanoparlantes, que han importado directamente el vocablo citado, gamification, del inglés game (juego), traducido directamente como gamificación. Para referirse a fenómenos iguales o similares, en castellano también usan otros neologismos, por ejemplo, ludificación o juguetización. No obstante, considero desafortunadas y disonantes las tres últimas designaciones en esta lengua. Podrían buscarse otras denominaciones con sentido equivalente que mantuviesen la corrección idiomática, siguiendo las pautas generales dadas por Lázaro Carreter (1997: 575590). Por ejemplo, sería preferible hablar de didáctica lúdica para sustituir a ludificación o juguetización, y, en vez de gamificación, usar alternativas como juegos didácticos, juegos formativos, o los ya citados juegos educativos. Si se busca la brevedad, tales propuestas se prestarían a ser denominadas por sus siglas, tan de moda actualmente. 


\section{MOTIVOS PARA COMPLEMENTAR CON JUEGOS LA DOCENCIA DE PALEOGRAFÍA DE LECTURA}

La Paleografía es una disciplina que estudia la antigua (paleo-) escritura (-grafía). Entre sus especialidades está la paleografía práctica o de lectura, centrada en leer textos antiguos, hacia la que se enfocan los juegos aquí mencionados.

Es común que el aprendiz encuentre difícil leer grafías de documentos cuyos sistemas escriturarios han caído en desuso (Figura 1). Identificar las letras separadas de un documento antiguo plantea dificultades, que se multiplican cuando unas letras ligan con otras, distorsionando sus formas puras, o cuando no se separan las palabras (scriptio continua). Y a ello deben enfrentarse los alumnos, que acostumbran a considerar difícil leer los documentos antiguos. Muchos dejan de asistir a clase de paleografía y pocos se especializan en dicha materia, la cual goza de mala reputación y queda cada vez más relegada en los planes docentes de las universidades.

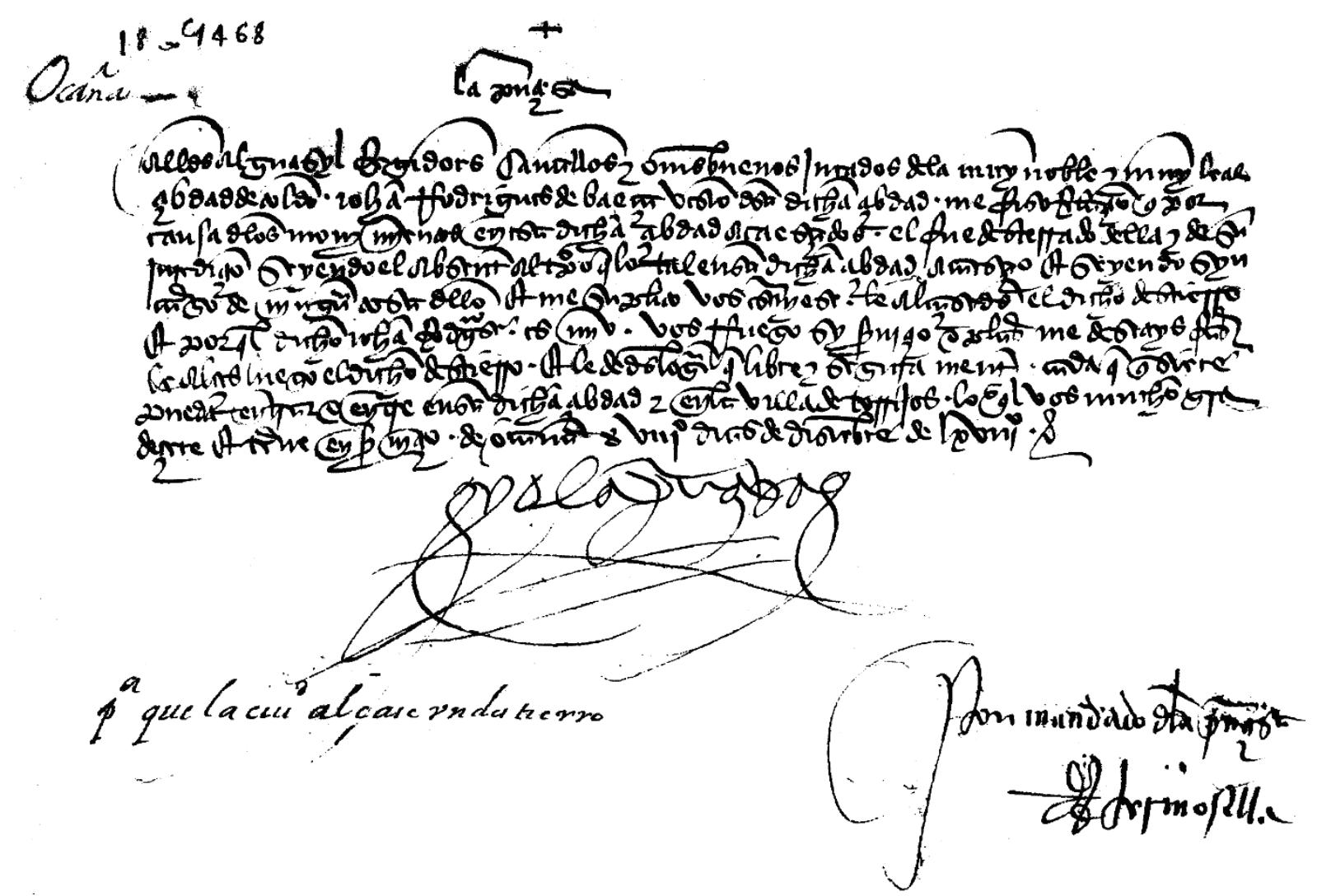

Figura 1. Ejemplo de documento binarizado (Zozaya-Montes, 2012a: 368).

Las clases de Paleografía de diversas universidades españolas consisten en lo siguiente. El docente selecciona una copia de un texto antiguo, que el alumno va leyendo en voz alta, por líneas y pasando el turno al siguiente. A la par, el docente ha de supervisar y cuando proceda-corregir evidenciando qué letra es y por qué. En la fórmula descrita es 
común que el estudiante haga trampas, mirando la transcripción resuelta, o que se adelante previendo qué renglón le tocará, para leerlo en silencio. Así, pierde el hilo y desatiende la lectura común. Todo ello provoca reiteraciones cansinas y desemboca en una pérdida sustancial de tiempo.

En la docencia de Paleografía tradicional he observado algunos problemas manifestados en numerosos alumnos. Uno: escuchar la lectura ajena en voz alta les aburre. Otro: tener que leer un texto en voz alta les genera inseguridad, temiendo la crítica o la mofa ante los fallos, que son tan naturales como probables. La consecuencia es que muchos estudiantes desatienden. Así, finalmente, no aprenden a discernir bien las letras independientes, que es un paso elemental muy importante para leer un documento antiguo. Al no dominarlo, se desmotivan y desaniman con facilidad.

Para ser competente leyendo textos antiguos, es primordial adquirir una base sólida, identificando los rasgos de cada letra. Si estos se asimilan, después será más fácil leer otras grafías asociadas que ligan, formando palabras, conformando las oraciones del texto. Para aprenderlo hay varias técnicas complementarias a la lectura. Una fundamental es estudiar con alfabetos $^{3}$, como el de la Figura 2.

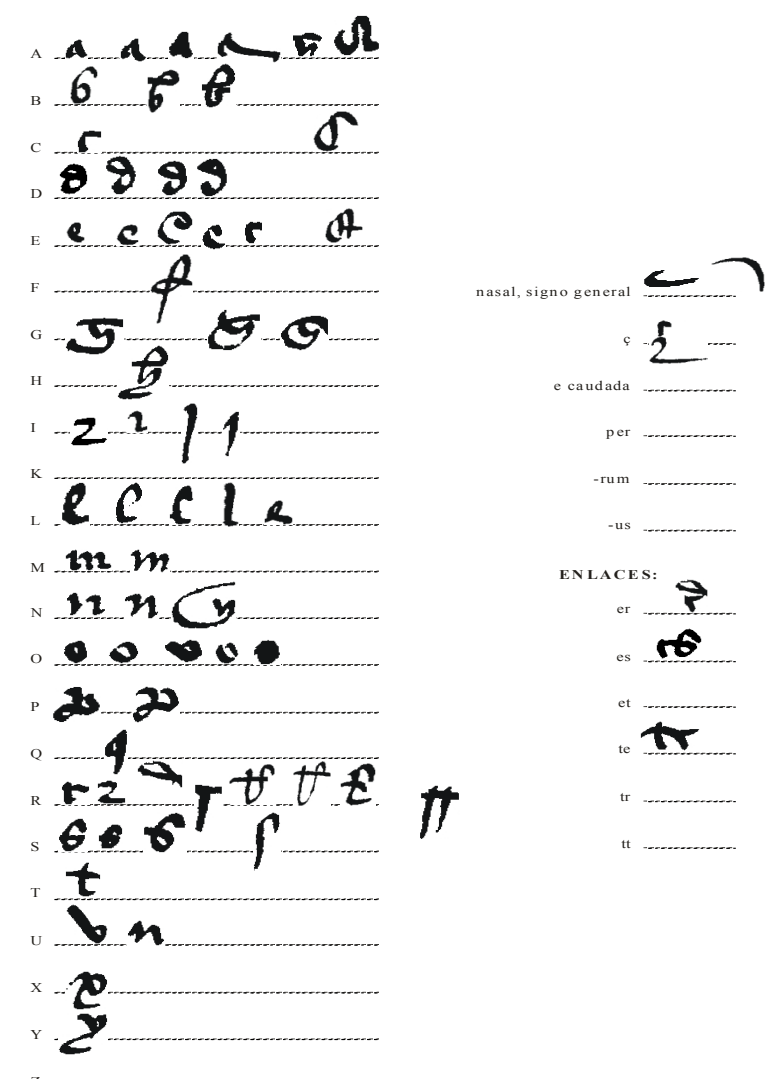

Figura 2. Alfabeto en letra cortesana (Zozaya-Montes, 2012a: 369).

\footnotetext{
${ }^{3}$ El blog de Paleografía y ciencias afines dispone gratuitamente de plantillas vacías de alfabetos y abreviaturas (accesible desde http://paleografia.hypotheses.org/)
} 
Otra técnica de aprendizaje colateral podría conjugar métodos más entretenidos para reforzar el estudio de la paleografía y practicar los conocimientos adquiridos, jugando. Con ellos se ayudará a que los alumnos se relajen, se distraigan, disfruten y resten importancia a la concentración que exige aprender materias tan densas como la paleografía. La intención, común a otros proyectos docentes, es conseguir que leer escrituras antiguas parezca un pasatiempo, más que algo aburrido y estresante (Zozaya-Montes, 2014a: 155-170).

Los juegos didácticos de paleografía son especialmente útiles para ayudar a identificar las grafías antiguas y a desarrollar abreviaturas. Ambas prácticas pueden ejercitarse con actividades lúdicas basadas en el mecanismo de prueba y error. Este sistema ayuda a seleccionar, repetir y consolidar las acciones acertadas, mientras se rechazan los conocimientos erróneos. Con ello, se acelerará la maduración de las aptitudes, de forma consciente e inconsciente, de una forma intuitiva, auxiliada por mecanismos como la repetición o la memoria visual.

Se recomienda que jueguen durante los últimos minutos de una sesión de estudio, cuando el aprendiz esté cansado, para incentivar, premiando el esfuerzo intelectual realizado. También los ratos perdidos son propicios para practicar con juegos interactivos, accediendo desde los dispositivos móviles en contextos ajenos a la docencia tradicional.

El ambiente académico actual cada vez es más propicio a introducir didácticas lúdicas en la enseñanza universitaria, lo cual facilitaría la acogida de la presente propuesta, máxime cuando los avances de la técnica computacional aplicados a la Paleografía Digital han conseguido logros como los mencionados a continuación, que también cambian la percepción de la Paleografía por parte del alumnado, y condicionan su demanda.

\section{CONTEXTO DE INNOVACIONES EN HUMANIDADES DIGITALES $Y$} PALEOGRAFÍA DIGITAL

Las NTIC también se han desposado exitosamente con disciplinas densas como la Paleografía, en un contexto donde la difusión de las Humanidades Digitales ha sido intensa. Se han ingeniado múltiples posibilidades antes inimaginables, brindando un contexto propicio para que las novedades científicas se pusiesen al servicio de la paleografía y de otras materias afines, como la Codicología (Rehbein et al., 2009; Fischer et al., 2010).

El gran público percibe que la llamada Era Digital ha llegado a la Paleografía o la Archivística gracias a que cuantiosas instituciones oficiales públicas y privadas del mundo están digitalizado miles de manuscritos en color, con una calidad magnífica, disponibles 
gratuitamente en línea ${ }^{4}$. Por afinidad con la lengua castellana, baste aquí traer el ejemplo representativo de Pares ${ }^{5}$, el Portal de Archivos Españoles (Sánchez Mairena, 2014: 1-21).

Tales espacios virtuales con documentación de libre acceso en la red cuentan con múltiples ventajas. Permiten, por ejemplo, obtener material docente con el fin de practicar paleografía de lectura, pero también acceder a fuentes primarias para investigar en línea, o a cualquier hora y desde cualquier parte del planeta, sin costes añadidos (Zozaya-Montes, 2012b: 119-120). Esa labor es aún más provechosa para el alumno que ya conoce páginas académicas de calidad, y así evita algo común, desorientarse ante la infinita información que ofrece Internet (Zozaya-Montes, 2009: 240-248; Castro Correa, 2014: 211-228).

Para un público especializado, la alianza interdisciplinar con la tecnología está produciendo proyectos sorprendentes en el campo de la Paleografía Digital. El potencial de ciertos programas se ha demostrado incluso en algunos inacabados (Ciula, 2005: 1-31). Todo ello resulta de gran utilidad, aunque los avances rendirían mayores éxitos si se cooperase más en la normalización de resultados (Stutzmann, 2010: 247-277).

Actualmente se están creando recursos excelentes con potentes bases de datos sobre escritura manuscrita. Algunos ejemplos son ya dechados de referencia internacional, como DigiPal $^{6}$ (Brookes et al., 2015: 25-58) más Models of Authority ${ }^{7}$ (Webber, 2015: 177-180). Entre otras utilidades, describen y etiquetan tipos de letras y de signos gráficos, catalogando la información tópica y cronológica que se desprende de las grafías de la forma más objetiva posible, usando métodos cuantitativos (Stokes, 2009: 309-338).

Gracias a proyectos de ese estilo, va existiendo un contexto internáutico donde es normal ver facsímiles de documentos antiguos interactivos con grafías segmentadas coloreadas, muy atrayentes visualmente. Eso ayuda a cambiar la percepción de la materia paleográfica como algo más fresco, espontáneo y colorido, alejada de la común lámina bicolor estática. Cada vez más proyectos vinculados a la tecnología van haciendo que se tiña de modernidad una materia tan densa.

Además, la interdisciplinariedad también ha afectado a la paleografía en más campos. Por ejemplo, se han desarrollado notablemente programas de reconocimiento automático de caracteres de documentación antigua. Estos se basan -simplificando- en programar a los ordenadores para que lean manuscritos antiguos, por lo común, sobre la base de métodos OCR (Optical Character Recognition). Son proyectos innovadores que continúan buscando

\footnotetext{
${ }^{4}$ Se reúne ese tipo de enlaces académicos de rigor científico en Zozaya-Montes (2012-2016), accesible desde http://paleografia.hypotheses.org/on-line-archivos-digitales/recursos-digitalizados-de-libre-acceso-free-onlinesources.

${ }^{5}$ Accesible desde http://pares.mcu.es.

6 Digital Resource and Database of Manuscripts, Palaeography and Diplomatic (DigiPal). Accesible desde http://www.digipal.eu.

${ }^{7}$ Accesible desde http://www.modelsofauthority.ac.uk. Models of Authority. Scottish Charters and the Emergence of Government, 1100-1250.
} 
soluciones ingeniosas a las limitaciones que presentan los computadores transcribiendo letras y abreviaturas (entre otros, Stokes, 2008; Wolf et al., 2011: 3545-3548; Malagón et al., 2012: 337-342; Fernández-Mota et al., 2014; 293-312).

Ante este contexto, se aprecia el interés que despierta la escritura antigua, de forma que la paleografía se abre cada vez a más disciplinas como la óptica, la topología o la informática computacional. Otro terreno es el lúdico, donde la paleografía sólo ha entrado tímidamente, por ahora.

\section{JUEGOS DE PALEOGRAFÍA INTERACTIVOS EN EL PANORAMA} INTERNACIONAL

Los avances de la Paleografía Digital también se aprecian en el campo de la docencia en línea. Ello está ampliando y modificando los métodos de investigación pedagógica ${ }^{8}$, que, en cualquier caso, deben apoyar -pero no reemplazar- al docente humano (Stokes, 2010: 229-425). Los denominados tutoriales, en muchos casos, también han transformado las formas de acercarse al material de estudio por parte del alumnado (Cartelli y Palma, 2009: 123-134).

Existen numerosos cursos virtuales gratuitos en línea de paleografía que incluyen ejercicios de lectura. De diseño atrayente, moderno y cuidado, tienen una apariencia lúdica. Acostumbran a ser tan intuitivos y sencillos que en ocasiones no es imprescindible saber leer el idioma del curso para leer un facsímil escrito en esa u otra lengua. Podrían citarse varios como: English Handwriting (1500-1700) ${ }^{9}$, Interactive Album of Mediaeval Palaeography ${ }^{10}$, Latin Palaeography ${ }^{11}$, Medieval Writing ${ }^{12}$, Palaeography ${ }^{13}$, Medieval Palaeography ${ }^{14}$, Script Tutorial $^{15}$, Scriptorium (Medieval and Early Modern Manuscripts Online) ${ }^{16}$, Scriptorium (Tutorial de Paleografia i Diplomática) ${ }^{17}$, Spanish Palaeography Digital and Learning Tool (en inglés, pero con facsímiles interactivos en español $)^{18}$ o Theleme ${ }^{19}$.

Muchos de ellos incluyen ejercicios interactivos para practicar cómo desarrollar ciertas abreviaturas, o cómo leer ciertas letras, palabras o frases escritas con caracteres antiguos. Tienen varias denominaciones: ejercicio interactivo, tutorial, tutorial práctico en línea o

\footnotetext{
${ }^{8}$ Un blog para reflexionar sobre los métodos docentes es Teaching the Codex. Pedagogical Approaches to Palaeography and Codicology https://teachingthecodex.wordpress.com.

${ }_{19}^{9}$ Accesible desde http://www.english.cam.ac.uk/ceres/ehoc/index.html.

${ }_{11}^{10}$ Accesible desde http://ciham.ish-lyon.cnrs.fr/paleographie/index.php?l=en.

${ }^{11}$ Accesible desde http://www.nationalarchives.gov.uk/latinpalaeography/.

${ }_{12}$ Accesible desde http://medievalwriting.50megs.com/writing.htm.

${ }_{13}^{13}$ Accesible desde http://www.nationalarchives.gov.uk/palaeography/.

${ }_{14}^{14}$ Accesible desde http://paleo.anglo-norman.org/medfram.html.

${ }_{15}^{15}$ Accesible desde https://script.byu.edu/Pages/home.aspx.

${ }_{17}^{16}$ Accesible desde http://scriptorium.english.cam.ac.uk.

17 Accesible desde http://www.ub.edu/contrataedium/scriptorium/web/.

${ }^{18}$ Accesible desde http://spanishpaleographytool.org.

${ }^{19}$ Accesible desde http://theleme.enc.sorbonne.fr/dossiers/.
} 
actividad de formación, lo cual se ilustrará posteriormente con algún ejemplo. Sin embargo, las palabras juego y lúdica no suelen aparecer, aunque acaso sí podrían incluir tal denominación.

De esos once cursos $^{20}$, sólo en la página Palaeography ${ }^{21}$ (de los Archivos Nacionales del Reino Unido) se halla un juego así designado, el Ducking Stool Game. Este se inspira en un antiguo tipo de tortura y escarnio público. Consistía en atar a una silla a la persona acusada, normalmente, mujer; tras cierto protocolo, sería sumergida en el agua una o más veces (Figura 3). El juego muestra una xilografía con una condenada, a quien se salva de la zambullida transcribiendo correctamente ciertas palabras (Zozaya-Montes, 2014b: 475-484). El curso fue candidato a los premios The Times Higher Awards 2006 al uso más imaginativo para el aprendizaje a distancia ${ }^{22}$, hecho que recuerda la importancia de valorar la imaginación en la docencia (Rodari, 1983).

\section{Palaeography}

\section{The ducking stool game}

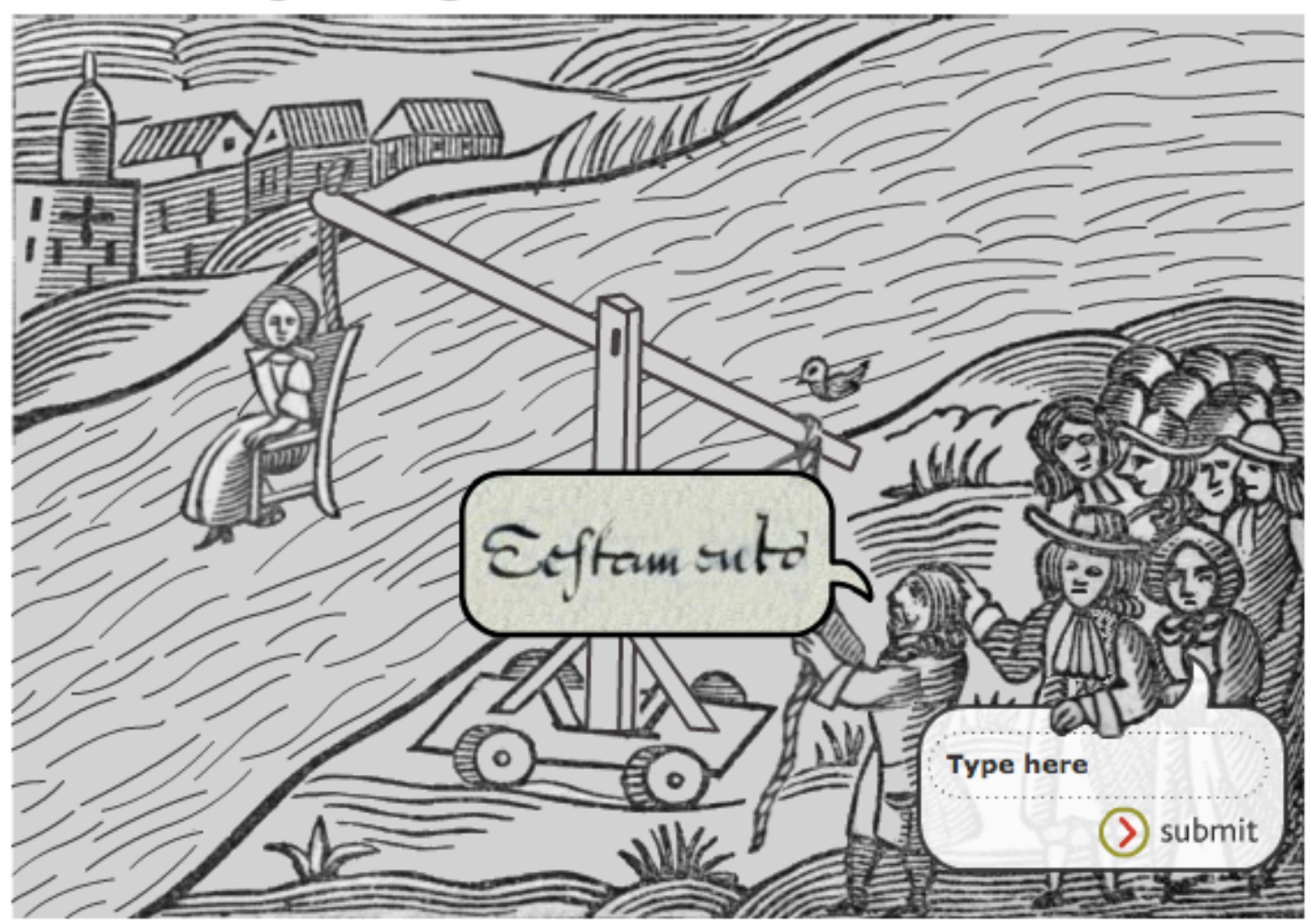

Woodcut of ducking stool taken from G.F.Townsend, 'The Town and Borough of Leominster', (1863).

Figura 3. Juego del Ducking Stool Game (TNA).

\footnotetext{
${ }^{20}$ En este estudio quedan al margen juegos que no están especializados en paleografía, aunque se vinculan al mundo de la escritura antigua, como los juegos lingüísticos creados por el profesor Daniele Fusi, en Fusisoft, sobre un ábaco epigráfico o de un generador de anagramas. Accesible desde http://fusisoft.azurewebsites.net. ${ }_{21}^{21}$ Accesible desde http://www.nationalarchives.gov.uk/palaeography/.

22 Accesible desde http://personal.ee.surrey.ac.uk/Personal/L.Wood/cleo/awards/thes/thes-awards-2006finalists.pdf, sin paginar y sin datos de edición.
} 
Aparte del Ducking Stool Game, en aquellos once cursos interactivos en línea no he hallado más ejercicios que reciban la denominación de juegos o actividades lúdicas, cuando sí podrían haber tildado alguno así. Por ejemplo, dentro del curso Latin Palaeography (también de los citados Archivos Nacionales) ${ }^{23}$, está el apartado Match Abbreviations (empareja abreviaturas). Hay que unir cada abreviatura con su correspondiente palabra desarrollada, mientras un monje parpadeante -un personaje animado- vigila al jugador (Figura 4). De acuerdo con la web, eso es "una actividad de formación [...] para probar tu conocimiento de las abreviaturas" 24 .

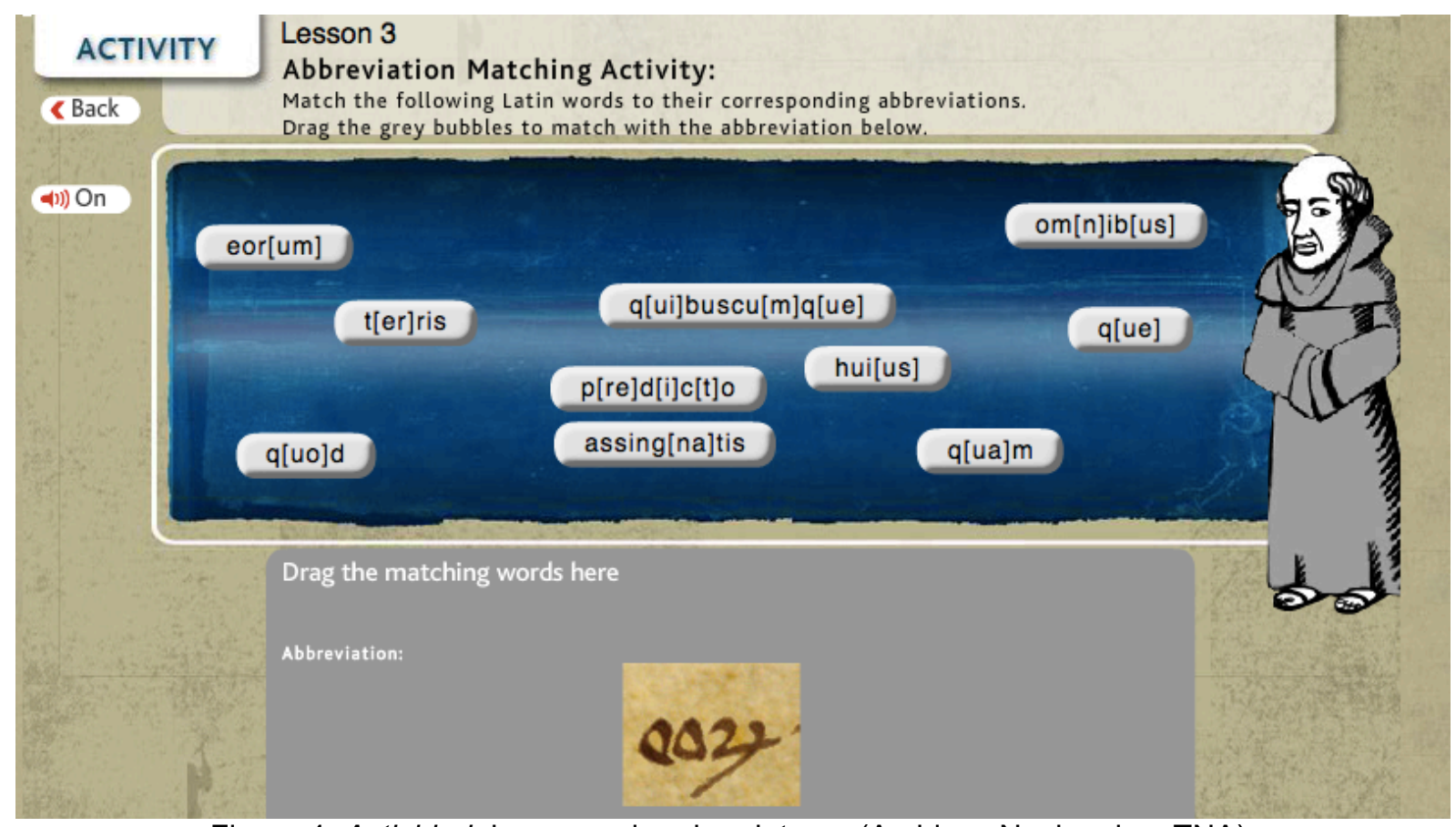

Figura 4. Actividad de emparejar abreviaturas (Archivos Nacionales, TNA).

Sin embargo, opino que Match Abbreviations también podría considerarse un juego, atendiendo a la definición propuesta inicialmente. Primero, es una actividad que tiene la intención de entretener. Segundo, cuenta con reglas, pues hay que vincular correctamente abreviaturas y palabras antiguas para seguir avanzando. Tercero, se desarrolla en un marco artificial de apariencia lúdica, al estar ambientado por el dibujo de un monje que no quita ojo. Además, siguiendo ya otras definiciones de juego, se gana algo: la aprobación del clérigo, quien incluso te regala algún guiño, al margen de la congratulación general si se finaliza correctamente.

Además de los cursos digitales interactivos de paleografía, cuyo fin es enseñar dicha materia desde un punto de vista académico, hay otros lugares virtuales en Internet sobre

\footnotetext{
${ }^{23}$ Accesible desde http://www.nationalarchives.gov.uk/latinpalaeography/.

24. "(...) a learning activity (...) to test your knowledge of the abbreviations" (traducción propia). Accesible desde http://www.nationalarchives.gov.uk/latinpalaeography/how-to-use.htm\#abbreviations.
} 
manuscritos antiguos con enfoque diferente, donde la paleografía es más un medio que un fin. Son páginas muy útiles que aúnan facsímiles y otros materiales digitalizados con ejercicios para practicar la lectura de documentación manuscrita antigua. Son herramientas que buscan otros objetivos: divulgar legados históricos, promover estudios sobre colecciones, difundir fuentes manuscritas digitalizadas, promocionar investigación histórica, sociológica, genealógica, etcétera.

Una de esas páginas es el Colonial American Handwriting ${ }^{25}$, de las colecciones digitales del Reed College (Oregon). Incluye, por un lado, el Early American Handwriting $\mathrm{Game}^{26}$ (juego de la temprana escritura manuscrita americana). Consiste en unir la grafía antigua con cada letra correspondiente en la actualidad, mientras un personaje dieciochesco dictamina si se unen correctamente (Figura 5). Por otro lado, la página tiene otro juego, de apariencia menos lúdica. Es el Abbreviations Game (el juego de las abreviaturas), donde se muestra una abreviatura con su grafía original, y se ofrecen varias alternativas para transcribirla. Al acabar, se propone que se verifique la puntuación, y, si es mejorable, se repita hasta lograr acertar todo ${ }^{27}$. Además, hay otros ejercicios para practicar, que en ocasiones denominan juegos ${ }^{28}$.

\footnotetext{
${ }^{25}$ Accesible desde http://cdm.reed.edu/cdm4/indianconverts/studyguides/colonial_american_handwriting/cultural_significance.php. ${ }^{26}$ Accesible desde http://www.reed.edu/handwriting/\#.

${ }^{27}$ Accesible

http://cdm.reed.edu/cdm4/indianconverts/studyguides/colonial american handwriting/abbreviations.php. desde ${ }^{28}$ Los denominan juegos en la columna de la izquierda de la página principal, a donde se accede desde las dos direcciones anteriormente citadas. En otras partes de la página no los denominan juegos.
} 


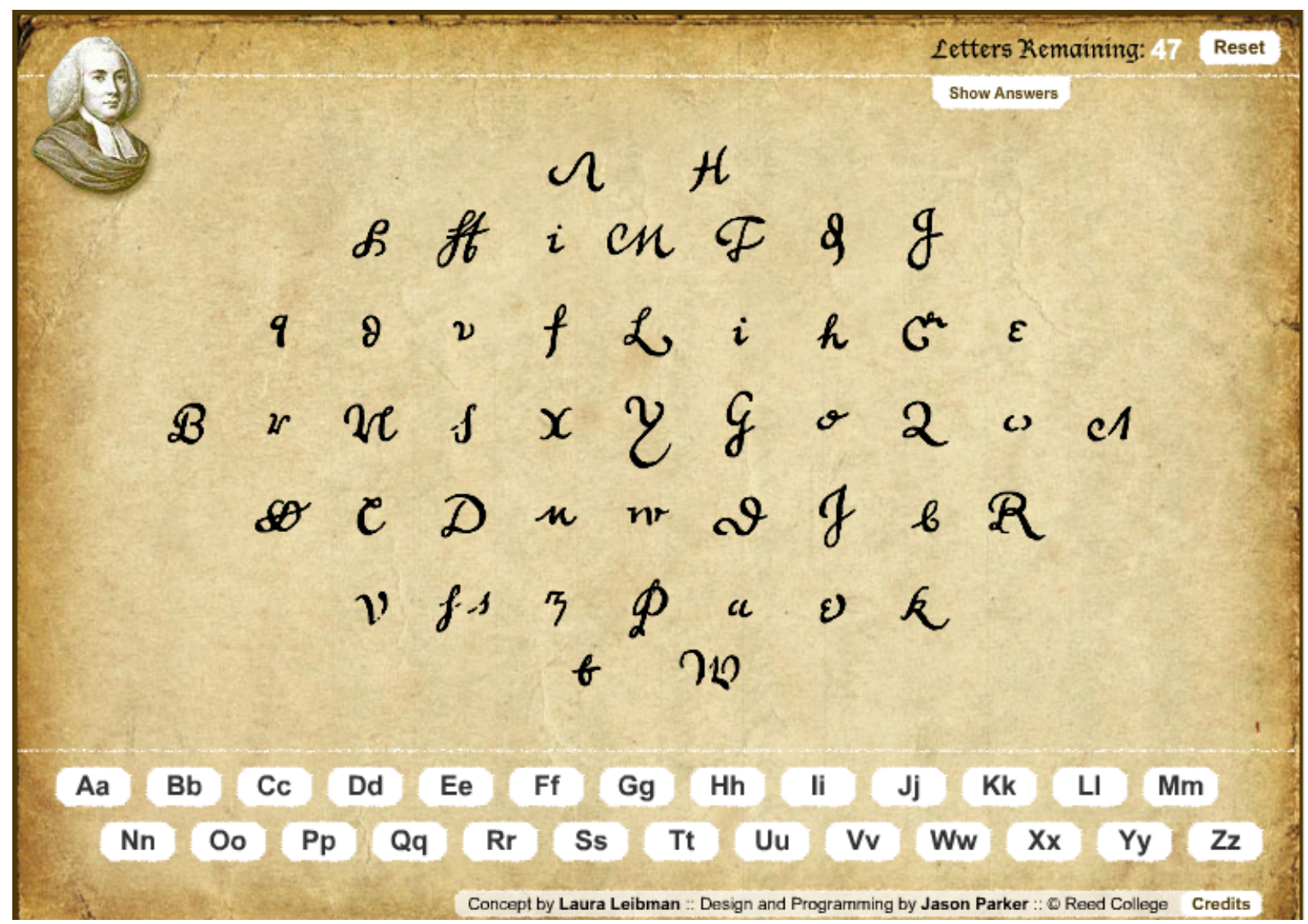

Figura 5. Juego Early American Handwriting Game.

Ejercicios similares para practicar lectura de Paleografía se hallan en unas y otras páginas, pero en los once cursos académicos de Paleografía esas actividades no se denominan juegos (aparte del Ducking Stool Game). Las intitulan, principalmente, actividad de formación, ejercicio interactivo, tutorial, o tutorial práctico en línea; sin embargo, muchas podrían designarse juego educativo, actividad lúdica educativa, o, directamente, juego, como en el Early American Handwriting Game.

Esas designaciones que oscilan entre el juego y el ejercicio pueden estar evidenciando varios hechos. Por un lado, manifiestan la dificultad de marcar la diferencia entre un juego y una actividad. Por otro lado, tales designaciones subjetivas acaso sean indicio de que los juegos no están bien vistos en la educación universitaria especializada en materias tan eruditas como la Paleografía.

\section{LA PALEOTECA: JUEGOS DIDÁCTICOS DE PALEOGRAFÍA Y BORRADORES} DE PROYECTOS

La Paleoteca es un espacio virtual con juegos paleográficos (Figura 6) ${ }^{29}$. Cuenta con varios tipos de juegos recreativos gratuitos. Los crucigramas tienen ya versión interactiva. El

\footnotetext{
${ }^{29}$ Accesible desde http://paleoteca.wordpress.com/.
} 
resto, compuesto por el paleo-poutpourrí, las paleoletras encadenadas, y las sopas paleográficas, por ahora tiene sólo versión para imprimir y jugar, preferiblemente con impresora en tres dimensiones (3D).

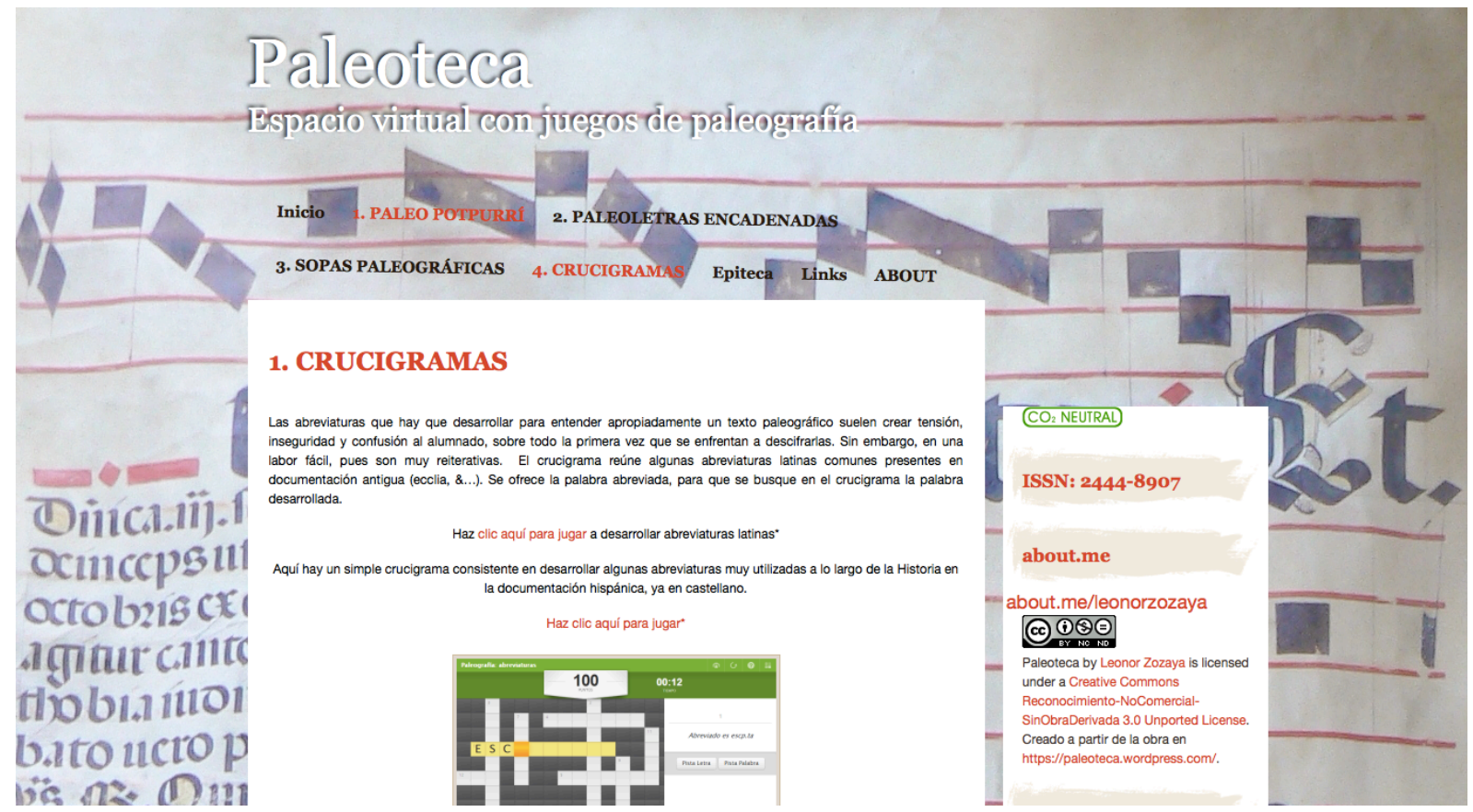

Figura 6. Imagen de la Paleoteca, espacio virtual con juegos de Paleografía.

Los juegos para imprimir tienen tablero y complementos, que son cartas o fichas, según proceda. El ejemplo aquí expuesto ofrece temporalmente una muestra en letra cortesana, que incluye copia del documento, binarizado en este caso (Figura 1), con un alfabeto (Figura 2) y la transcripción (Figura 7) ${ }^{30}$, útiles para los juegos expuestos en los apartados 7.2., 7.3. y 7.4. Estos patrones sirven por ahora simplemente para explicar en qué consiste el proyecto, aunque no se usen en el futuro, cuando haya juegos coloreados con más tipos de grafías como visigótica, gótica o humanística.

Además, respecto a los tipos gráficos, se intentará que el conjunto lúdico sea lo más completo posible desde el punto de vista científico y docente. Para ello, se prevé gestionar permisos para incluir grafías previamente segmentadas, descritas, catalogadas y analizadas en bases de datos y repertorios paleográficos académicos especializados. Así se pretende que, tras despertar la curiosidad en el jugador sobre el tipo de letra antigua usada, éste desee consultar las fuentes primigenias en un marco científico adecuado, donde encuentre información paleográfica y diplomática exhaustiva.

\footnotetext{
${ }^{30}$ El estudio del documento (publicado en Zozaya-Montes, 2012a: 365-370) formaba parte de un proyecto de investigación titulado "Nuevas estrategias didácticas y evaluativas para el aprendizaje de las Ciencias y Técnicas Historiográficas", Universidad Complutense de Madrid, núm. ref: 74. Investigadora Principal: Susana Cabezas Fontanilla. El proyecto tenía el objeto de difundir y dar a conocer documentación inédita del Archivo Municipal de Escalona (Toledo) y del Archivo del Monasterio de Santa María de Tórtoles (España).
} 
18 X U468 (18 decembre 1468).

[En letra humanística inclinada posterior:] Ocaña.

(Cruz)

La princesa:

Alcaldes, alguasyl, rregidores, caualleros, omes buenos, jurados de la muy noble y muy leal çibdad de Toledo: Iohan Rodrigues de Baeça, vesino desa dicha çibdad, me fiso rrelaçión que, por causa de los moujmientos en esa dicha çibdad acaesçidos, él fue desterrado della j de su jurediçión, seyendo él absente al tiempo que lo tal en esa dicha çibdad acaesyó, e seyendo syn cargo de ninguna cosa dello. E me suplicó vos escrivyese le alçásedes el dicho destierro. E por quel dicho Iohan Rodrigues es mío, vos rruego, sy seruicio e plaser me deseáys faser, le alcedes luego el dicho destierro, e le dedes logar que libre j seguramente cada [vez] que quisiere pueda entrar e entre en esa dicha çibdad j en la villa de Torrijos, lo qual vos mucho gradeçeré e terné en serviçio. De Ocaña, XVIII ${ }^{\circ}$ días de disiembre de LXVIII ${ }^{\circ}$.

Yo, la prinçesa (firma y rúbrica).

Por mandado de la princesa:

Hermosilla (firma y rúbrica).

[En letra humanística inclinada posterior:] Para que la ciudad alçase vn destierro.

Figura 7. Transcripción del documento reproducido en la Figura 1.

La Paleoteca aún se presenta en estado rudimentario, pero será mejorada, e intentará convertir todos los juegos en interactivos. Sobre todo, si logra reunir un equipo de voluntarios o algún mecenas que les financie el trabajo, y respete el mérito de la idea (Zozaya-Montes, 2015b). Para hacer la versión digital, caben diversas posibilidades. Una posibilidad consiste en usar programas gratuitos por sistemas de bloques (Build Your Own Blocks, BYOB), tales como Snap! ${ }^{31}$, o el primigenio Scracht. Este último pretende ayudar a los jóvenes a pensar de forma creativa, trabajando colaborativamente, para que desarrollen juegos y otras narraciones ${ }^{32}$. Este plan lúdico docente se completará con la edición de juegos de mesa.

Los juegos de la Paleoteca tienen por objeto ayudar a reconocer y a memorizar las formas de las letras ágilmente. Están pensados para un público amplio, desde curiosos en escritura antigua hasta estudiosos que deseen aprender sobre paleografía, especialmente archiveros, bibliotecarios, documentalistas, paleógrafos, filólogos, e historiadores (para epigrafistas ya existe la Epiteca; Zozaya-Montes, 2014b: 475-484). Para jugar es productivo formar grupos siempre que sea posible, para compartir conocimientos y favorecer la colaboración, la convivencia y el diálogo entre los participantes.

\footnotetext{
${ }^{31}$ Accesible desde http://snap.berkeley.edu/.

${ }^{32}$ Accesible desde htps://scratch.mit.edu/about/.
} 


\subsection{Crucigramas interactivos ${ }^{33}$}

Los crucigramas interactivos se desarrollan y hospedan en la plataforma educaplay. Sirven para aprender a desarrollar algunas abreviaturas latinas comunes en la documentación antigua, como en la Figura 8: abbi, que es abbati; \&, et; gra, gratia; kls, kalendas; nne, nomine; qd, quod; sci, sancti. Dicho juego usa las tipografías actuales, pero otros crucigramas incluirán fragmentos de imágenes facsimilares de abreviaturas. Se gana más puntuación acertando palabras, y se gana menos si se escribe mal la palabra, o si se piden pistas, tanto de letras como de palabras.

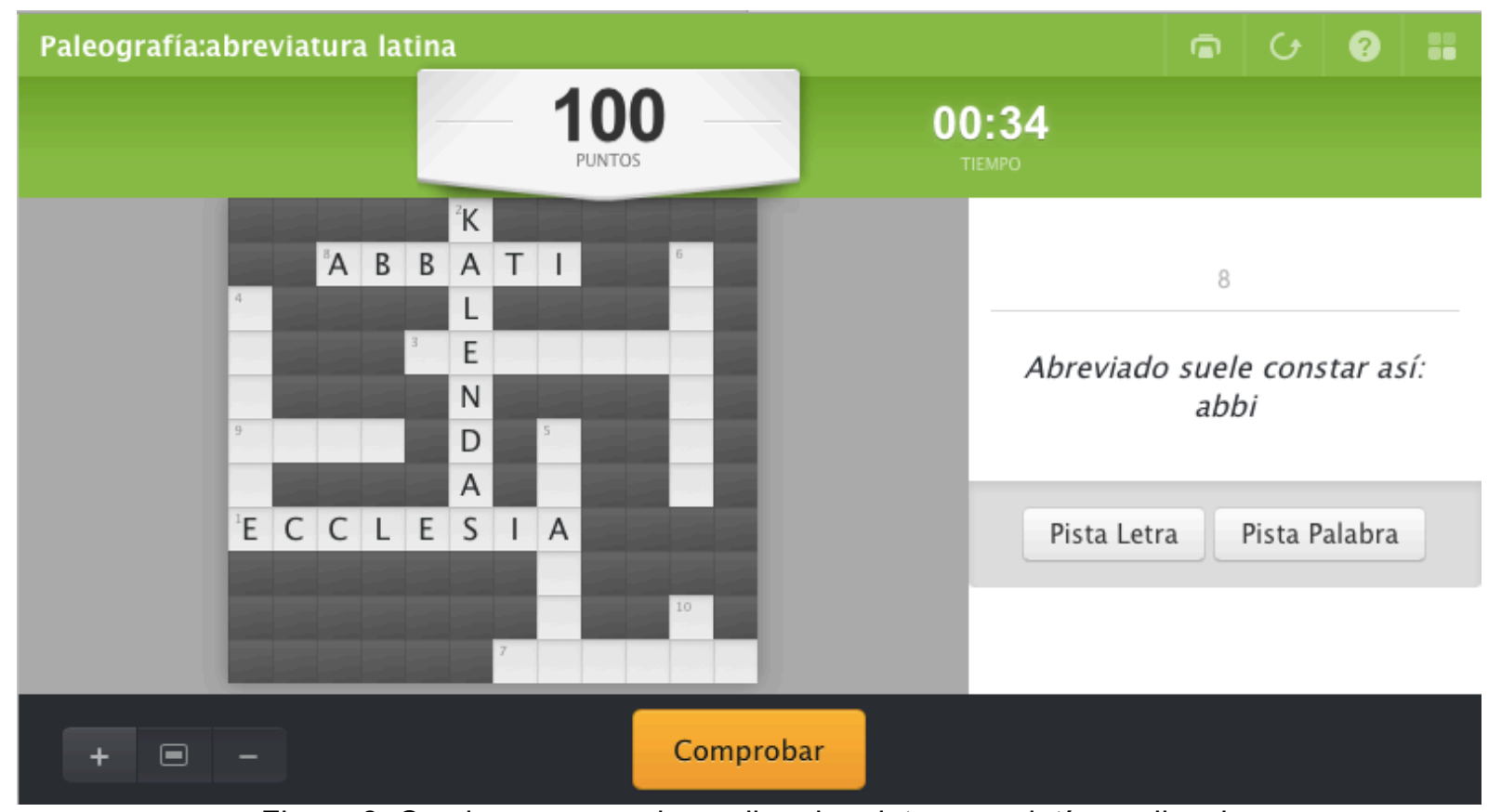

Figura 8. Crucigrama para desarollar abreviaturas en latín medieval.

\subsection{Juego del paleo-poutpourrí}

El juego del paleo poutpourrí -o poutpourrí paleográfico ${ }^{34}$ - tiene por objeto identificar letras. Los materiales son, por un lado, un tablero repleto de letras antiguas desordenadas, a modo de popurrí, que bautiza al juego (Figura 9). Por otro lado, hay cartas, cada una con la representación de cada una de esas letras antiguas, incluyendo su correspondiente transcripción abajo, en letra pequeña y del revés.

\footnotetext{
${ }^{33}$ En http://www.educaplay.com/es/recursoseducativos/2029563/html5/paleografia abreviatura latina.htm.

${ }^{34}$ Accesible desde https://paleoteca.wordpress.com/poutpourri-paleografico/.
} 


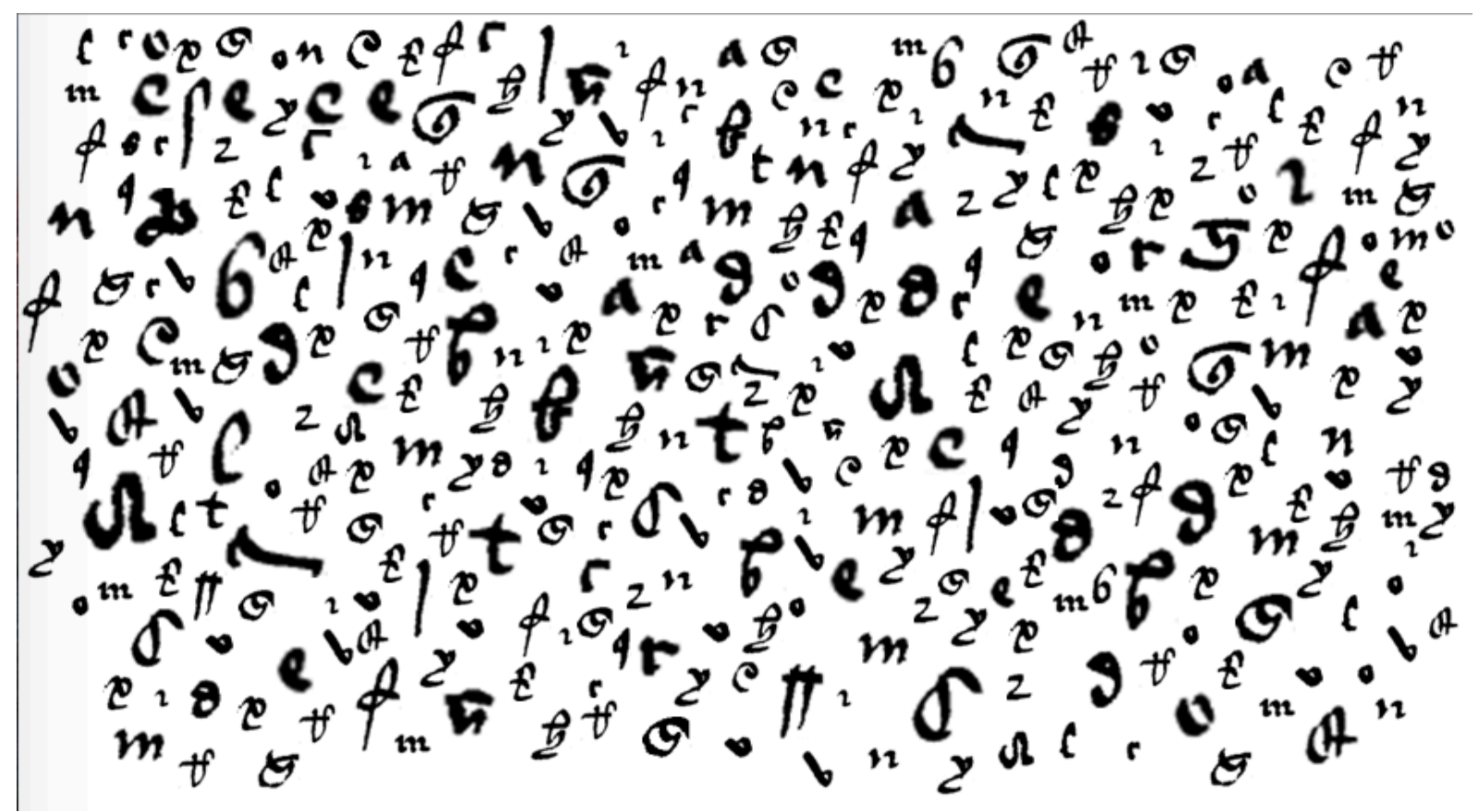

Figura 9. Soporte principal del paleo-poutpourrí, disponible en la Paleoteca.

Varios juegos son factibles con los mismos materiales. Uno es el siguiente. Sobre el tablero se colocan las cartas boca abajo. Estas se irán volteando, haciéndolas visibles una a una, y diciendo en voz alta qué letra hay (consta la transcripción). Seguidamente, los jugadores compiten por encontrar, en el tablero, la letra correspondiente a la carta. Quien la halle primero, gana un punto. Después, se repite la acción consecutivamente. Gana la baza quien llegue a los puntos pactados, por ejemplo: 10 para principiantes, 20 iniciados, y 27 aficionados, tantos como letras tiene el alfabeto actual.

Una versión digital interactiva del juego consistiría en lo siguiente. La pantalla (Figura 9) resalta una de las letras (por ejemplo, la erre), y hay que identificar todas las de su tipo, pulsando en ellas. Al acertar desaparece cada letra, lo cual suma puntos; los resta fallar, que colorea de verde las letras erradas. Desaparecido aquel tipo de letra (la erre, en ese caso), se repetirá la acción con nuevas letras, hasta dejar la pantalla vacía. Hay un tiempo limitado para acabar la partida y que el marcador pondere.

Otra versión interactiva tendría mayor movilidad: el juego de la lluvia de letras. Estas caen en sentido descendente, como una cascada, y se van acumulando en la parte inferior de la pantalla. Para que desaparezcan -dejando hueco a otras que bajen-, hay dos juegos. Uno: hay que identificar y pulsar sobre cierto tipo de letra (todas las erres, por ejemplo). Otro juego: hay que identificar y presionar sobre tipos de letras iguales que estén en contacto. Se logra mayor puntuación cuantas más letras se identifiquen en el menor tiempo posible, y aún más si son de diferente morfología. La velocidad de la lluvia de letras va aumentando. Acaba la partida cuando la pantalla se satura de letras, o cuando el participante vacía las convenidas. 


\subsection{Juego de la sopa paleográfica}

Consiste en jugar a las clásicas sopas de letras, pero con grafías antiguas ${ }^{35}$. En el ejemplo (Figura 10) hay que buscar palabras en horizontal: publico, debe, dinar, tela, y en vertical: deudas, arre, carta y testigo. Se permite acceder a la solución (Figura 11) ${ }^{36}$, y como en los demás, a la lámina original de la que proceden (Figura 1), su abecedario (Figura 2) o su transcripción (Figura 7), para practicar en su contexto original.
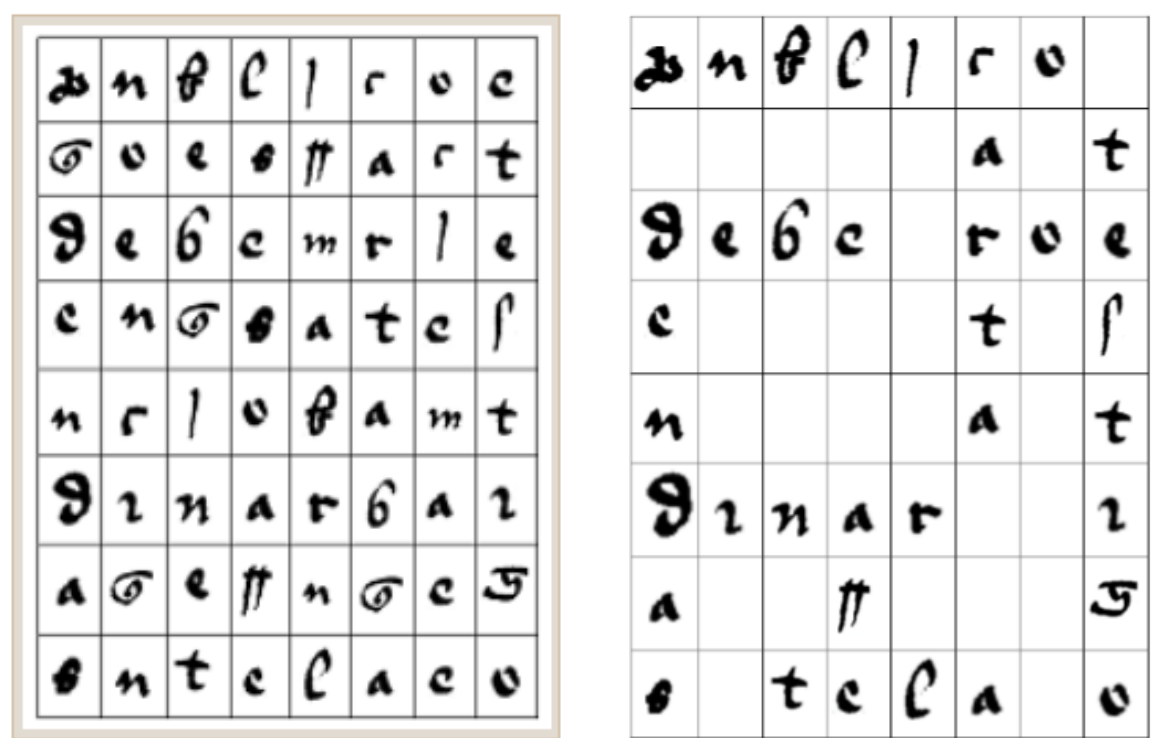

Figuras 10 (izquierda) y 11 (derecha). Sopa de paleoletras y su solución.

\subsection{Juego de las paleoletras encadenadas}

Se vale de letras antiguas para formar palabras ${ }^{37}$, y se inspira en el scrabble. El tablero está repleto de cuadrículas (Figura 12). Las fichas tienen una letra antigua dibujada, en cuya parte trasera constará la letra que representa con tipografía actual de imprenta, para despejar dudas. El idioma se pactará entre los jugadores (la Figura 12 también incluye latín).

\footnotetext{
${ }^{35}$ Accesible desde https://paleoteca.wordpress.com/sopas-de-paleografias/.

${ }^{36}$ Accesible desde $\mathrm{https}$ ://paleoteca.files.wordpress.com/2013/06/solucion-sopa-paleografica leonor-zozaya.pdf.

${ }^{37}$ Accesible desde https://paleoteca.wordpress.com/juego-de-letras-encadenadas/.
} 


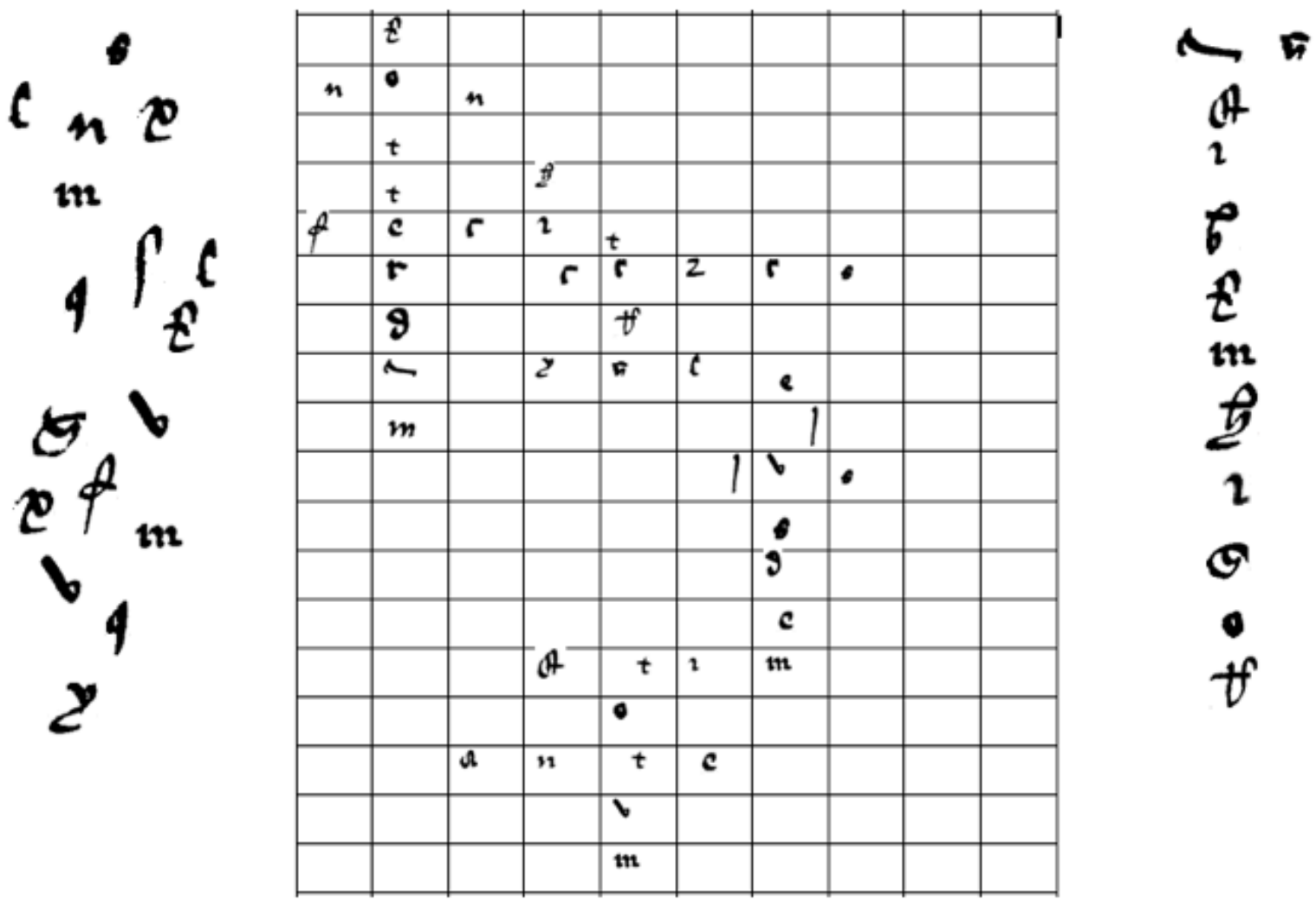

Figura 12. Paleoletras encadenadas: tablero más fichas de dos participantes.

Este juego se presta a varias versiones. Una consiste en repartir fichas de letras entre los concursantes. Comienza quien gane a pares o nones, siguiendo el turno dextrógiro. Los participantes han de juntar letras formando palabras. Quien no sepa qué palabra añadir, pasa el turno al cabo de un minuto. Se acabará cuando alguien se deshaga de todas las letras. Vale un punto la letra puesta, y dos puntos la letra encadenada con otra palabra. Gana quien coloque más letras en el tablero, con más letras encadenadas. La versión digital interactiva de este juego es fácil de imaginar, también jugando contra la máquina.

\section{BORRADOR DEL PROYECTO SANTOS, UN JUEGO DIGITAL DE} PALEOGRAFÍA

El presente proyecto es solo un borrador, y se titula Santos: A Game for History and Palaeography Lovers (Santos: un juego para amantes de la historia y la paleografía). Su estética se inspira en parte en el siglo XVIII, cuando vivió Santos. Francisco Santos (1722-¿?) era un clérigo ilustrado prácticamente desconocido hoy día debido a la censura inquisitorial y su posterior juicio, su encarcelamiento y huída (Zozaya-Montes, 2013: 151-166). En su honor toma su nombre el juego.

Se propone la versión de un borrador para desarrollar en soporte digital, abierto a sugerencias, mejoras y cambios, dependiendo también de las posibilidades de la informática. 
El borrador de la primera pantalla se presenta ahora en inglés, pero el resto está en español, para recordar que al menos habrá una versión bilingüe. La primera pantalla permite acceder a los siguientes comandos (Figura 13):

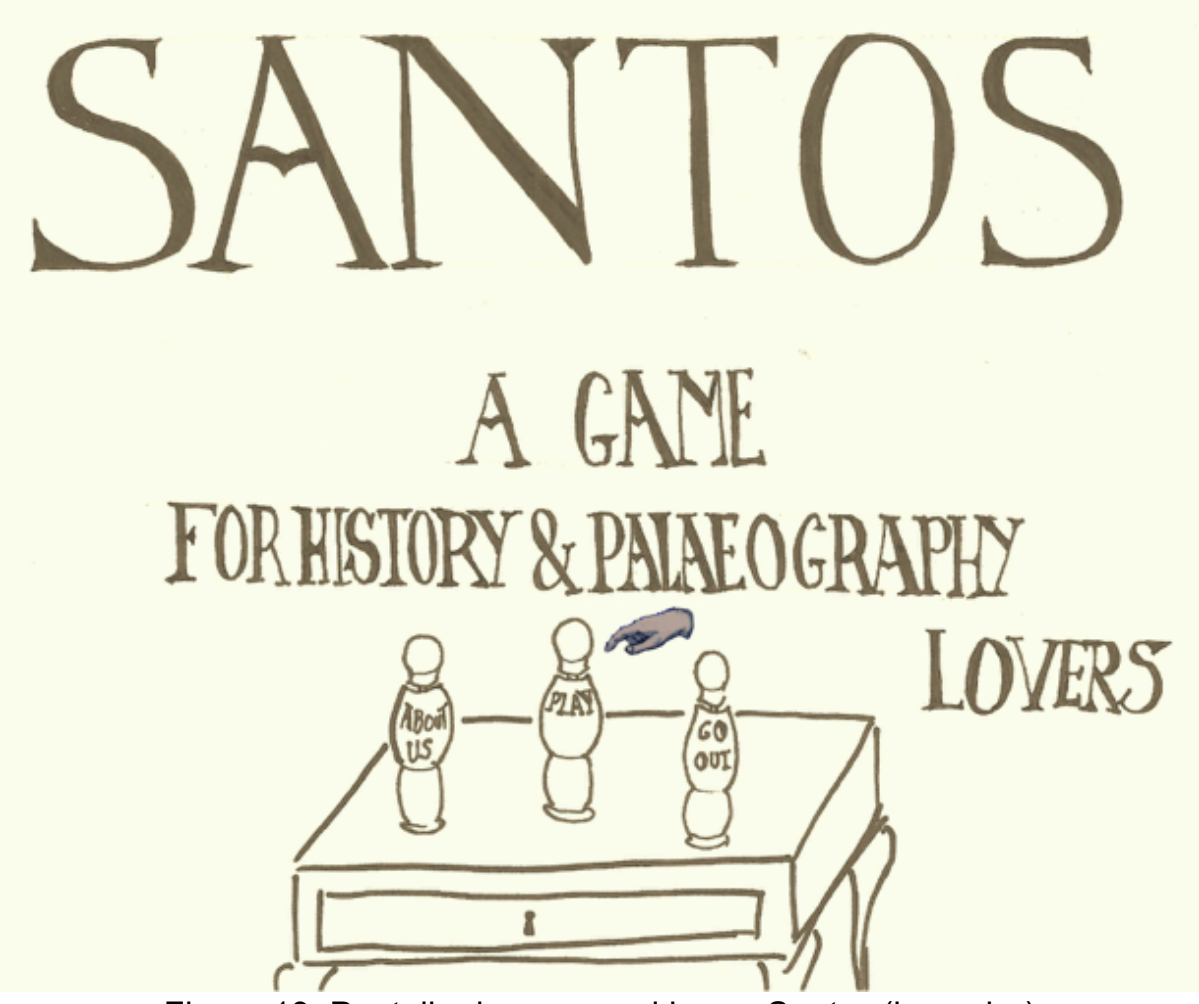

Figura 13. Pantalla de acceso al juego Santos (borrador).

- About (Sobre): incluye secciones informativas. Entre ellas, las referidas al propósito del juego y a sus fines docentes, a la información sobre fuentes y bibliografía, o a los agradecimientos. Incluye también el apartado de créditos, por ahora con dos personas en el equipo. Por un lado, José Moltó, músico y constructor de instrumentos de música popular de tradición oral, autor de los efectos especiales sonoros ${ }^{38}$. Por otro lado, Leonor Zozaya-Montes, autora del resto: la idea, el escrito, los textos y las imágenes, referidas a los dibujos y a las fotografías de materiales antiguos, cerámicos principalmente, más su tratamiento digital. El equipo requerirá además, como mínimo, incluir a un programador informático.

- Go out (salir): salida, cierre del programa.

\footnotetext{
38 Algunas de sus grabaciones sonoras que se usarán constan en https://pepemolto.wordpress.com y en https://musicos.hypotheses.org.
} 
- Play (jugar): da paso a la pantalla inicial (Figura 14). Comienza narrando lo siguiente: "Has logrado hacer un viaje al pasado. Apenas recuerdas nada, pues estás bajo el efecto de una pócima con la que te ha sedado el inquisidor". Ese sufrimiento de amnesia temporal justificará que se te faciliten pistas y claves. Continúa el texto:

[...] Bajo una identidad secreta, tienes la misión de hallar los libros y manuscritos que poseyó Francisco Santos. Esos se conservan, entre muchos otros documentos, en Gnosípolis, la ciudad del conocimiento, que fue creada bajo tierra con formas confusas para burlar a la Inquisición. Aunque no lo parezca, los espacios son infranqueables. Para superarlos, debes descifrar letras antiguas. Transcribiendo, franquearás la puerta invisible, subirás la escalera infinita o atravesarás el vano inconcluso, para, finalmente...

Has logrado hacer un viaje al pasado. Apenas recuerdas nada, pues estás bajo el efecto de una pócima con la que te ha sedado el inquisidor.

Bajo una identidad secreta, tienes la misión de hallar los libros y manuscritos que poseyó Francisco Santos. Esos se conservan, entre muchos otros documentos, en Gnosípolis, la ciudad del conocimiento, que fue creada bajo tierra con formas confusas para burlar a la Inquisición. Aunque no lo parezca, los espacios son infranqueables. Para superarlos, debes descifrar letras antiguas.

Transcribiendo, franquearás la puerta invisible, subirás la escalera infinita 0 atravesarás el vano inconcluso, para, finalmente...

Figura 14. Pantalla de introducción al juego Santos (borrador).

Tras leerlo, pulsas en la pantalla. Clic. Ya estás en Gnosípolis, lugar de extraños volúmenes cambiantes, formas engañosas, y sombras imposibles (Figura 15). Sus estructuras están atravesadas por un cordel gigante móvil, que te indicará dónde ir para avanzar de la forma más sencilla, en función de la dificultad de los enigmas. Sin embargo, no es imprescindible seguir su ruta. 


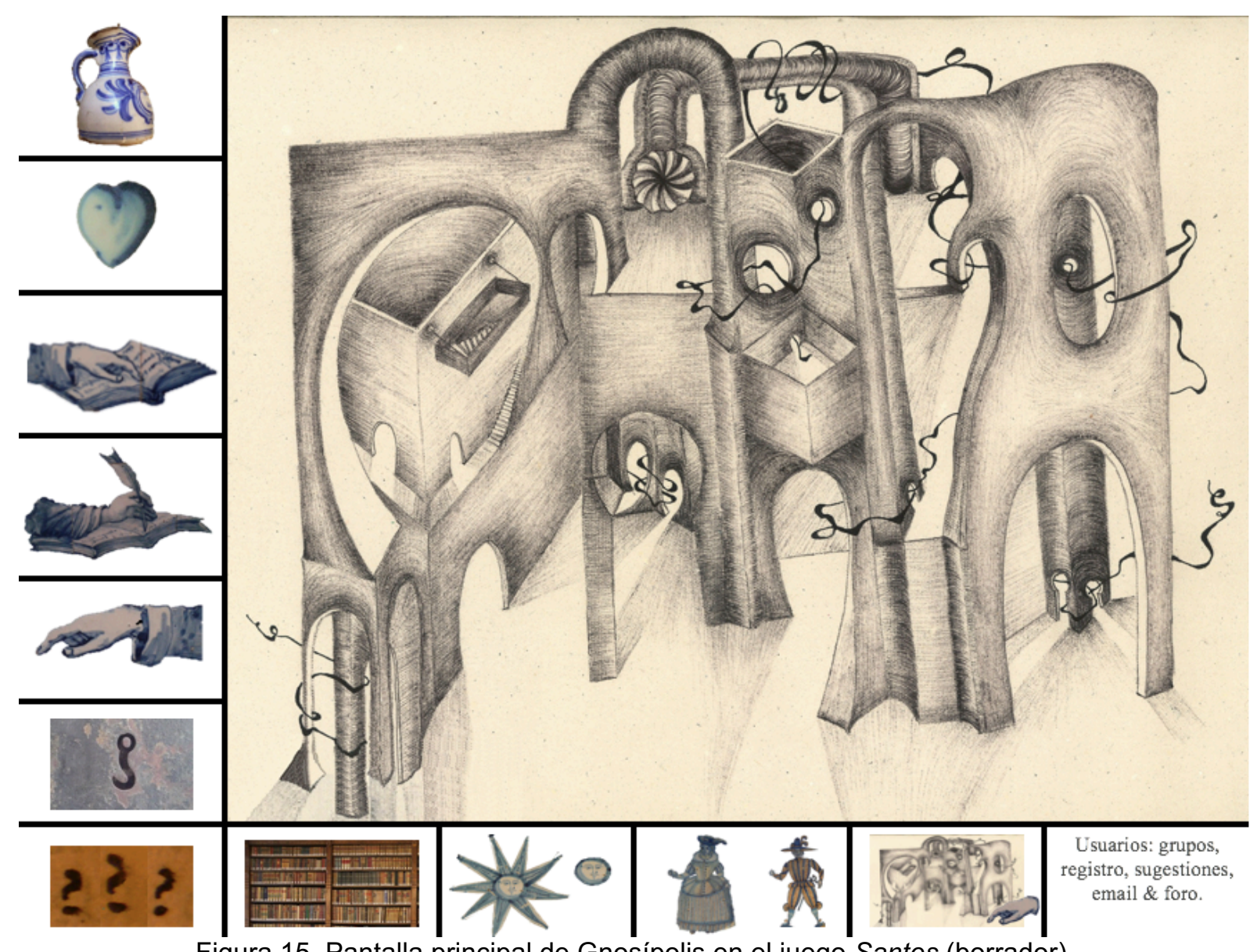

Figura 15. Pantalla principal de Gnosípolis en el juego Santos (borrador).

Los comandos, que permanecerán visibles durante todo tu periplo, se describen aquí empezando por la barra lateral izquierda, de arriba abajo:

- Jarra: contiene el brebaje que otorga conocimiento, llamado bálsamo de Fierabrás (nombre tomado del Quijote). Con él obtienes pistas y claves. Cuidado, no ingieras demasiado, o enfermarás, de forma que perderás libros y manuscritos.

- Corazón: opciones y preferencias. Permite elegir qué quieres: cambiar el lenguaje (español o inglés, en principio), solicitar subtítulos, voz, etcétera.

- Mano señalando un libro: ofrece información sobre temáticas aludidas directa o indirectamente en el juego. Por ejemplo, paleografía o historia: general, de la Inquisición, del personaje real de Francisco Santos, etcétera.

- Mano escribiendo: da acceso a las imágenes de los documentos que aparecen en el juego, así como los alfabetos más sus transcripciones. Tal como se citó, se prevé gestionar el uso de letras segmentadas de bases de datos académicas para ofrecer la información más completa posible.

- Mano señalando hacia la izquierda: vuelves a la pantalla anterior.

- Cerradura: terminas y sales del juego. 
- Signos de interrogación: para preguntar cuestiones técnicas como dónde estás, o qué tienes que hacer para avanzar.

[Continuando por la barra horizontal inferior, de izquierda a derecha:]

-Biblioteca: la de Francisco Santos, que debes completar al máximo para ganar el juego con la mejor puntuación. Libros y manuscritos equivalen a puntos, que ganas o pierdes conforme a tu intuición y conocimientos paleográficos. Si pierdes todos los documentos, se acaba tu travesía.

- Sol: medidor de tiempo. Según este transcurre, pierdes rayos del astro. Si éstos se acaban, sale la luna, llega la noche, y, con el ocaso, finaliza tu viaje. (Al jugar, inicialmente, sólo está el sol; la luna sólo aparece al perder.)

- Personajes: puedes elegir ser señora o soldado, entre otras posibilidades.

- Mapa de posición: indica dónde estás, tramos superados y por superar.

- Usuarios: grupos, registro, sugestiones y foro: espacio de individuos y grupos para registrarse, participar en el foro, enviar sugerencias y compartir experiencias. Incluirá encuestas.

Estando en Gnosípolis, el cordel gigante te indicará que entres por la puerta invisible, que da acceso al pasaje espiriforme, o de la falsa espiral (Figura 16).

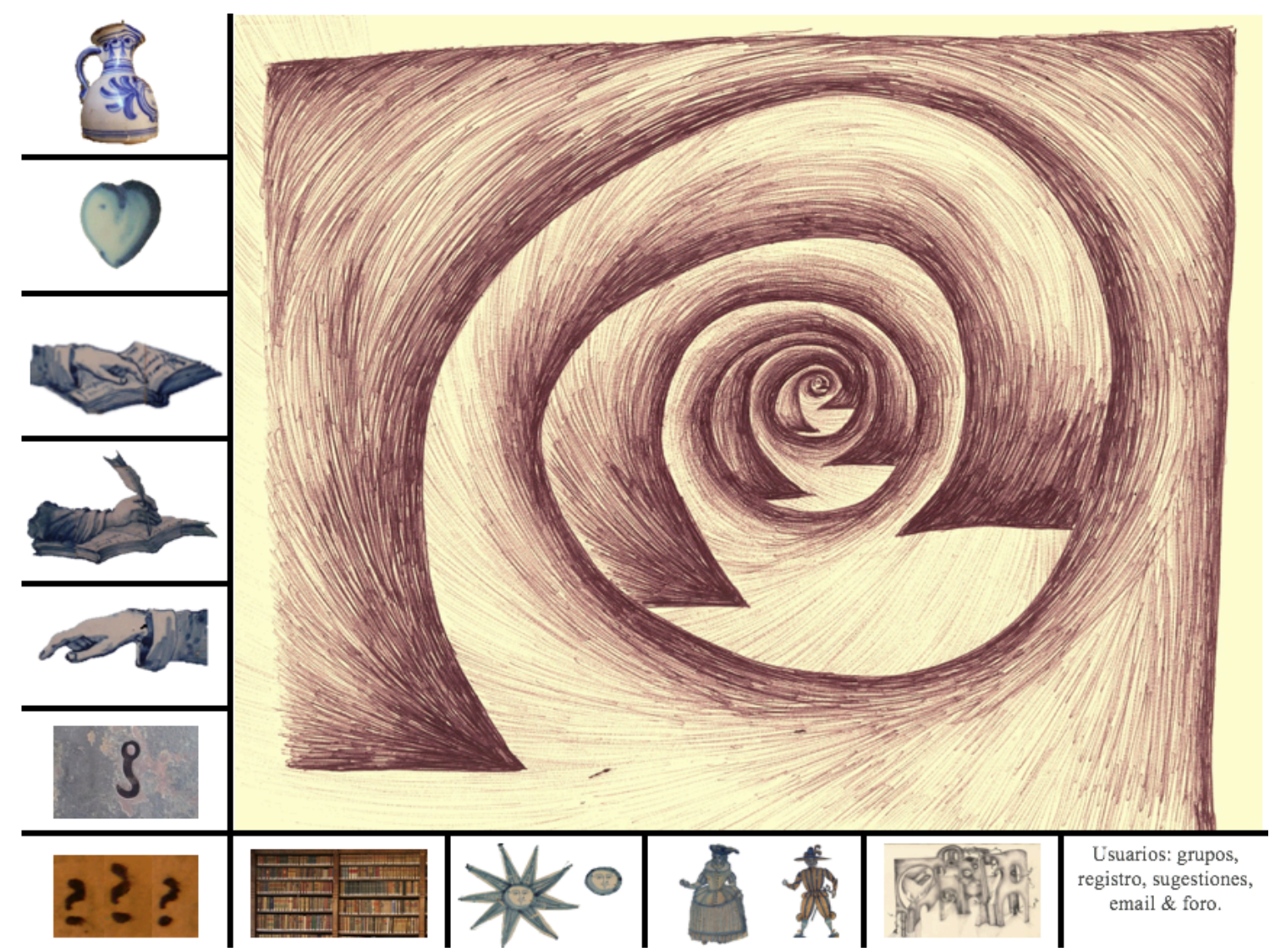

Figura 16. Pasaje espiriforme o pasaje de la falsa espiral. 
Para atravesar ese pasaje espiriforme has de acertar una adivinanza, escrita en caracteres antiguos (Figura 17). La mano -o manícula- es la forma que tendrá el cursor para escribir (primera línea a la derecha). Puedes beber del bálsamo de Fierabrás para obtener pistas de palabras o de letras. También podrás consultar el documento del que proceden los caracteres o el alfabeto, según se ha mencionado ya.

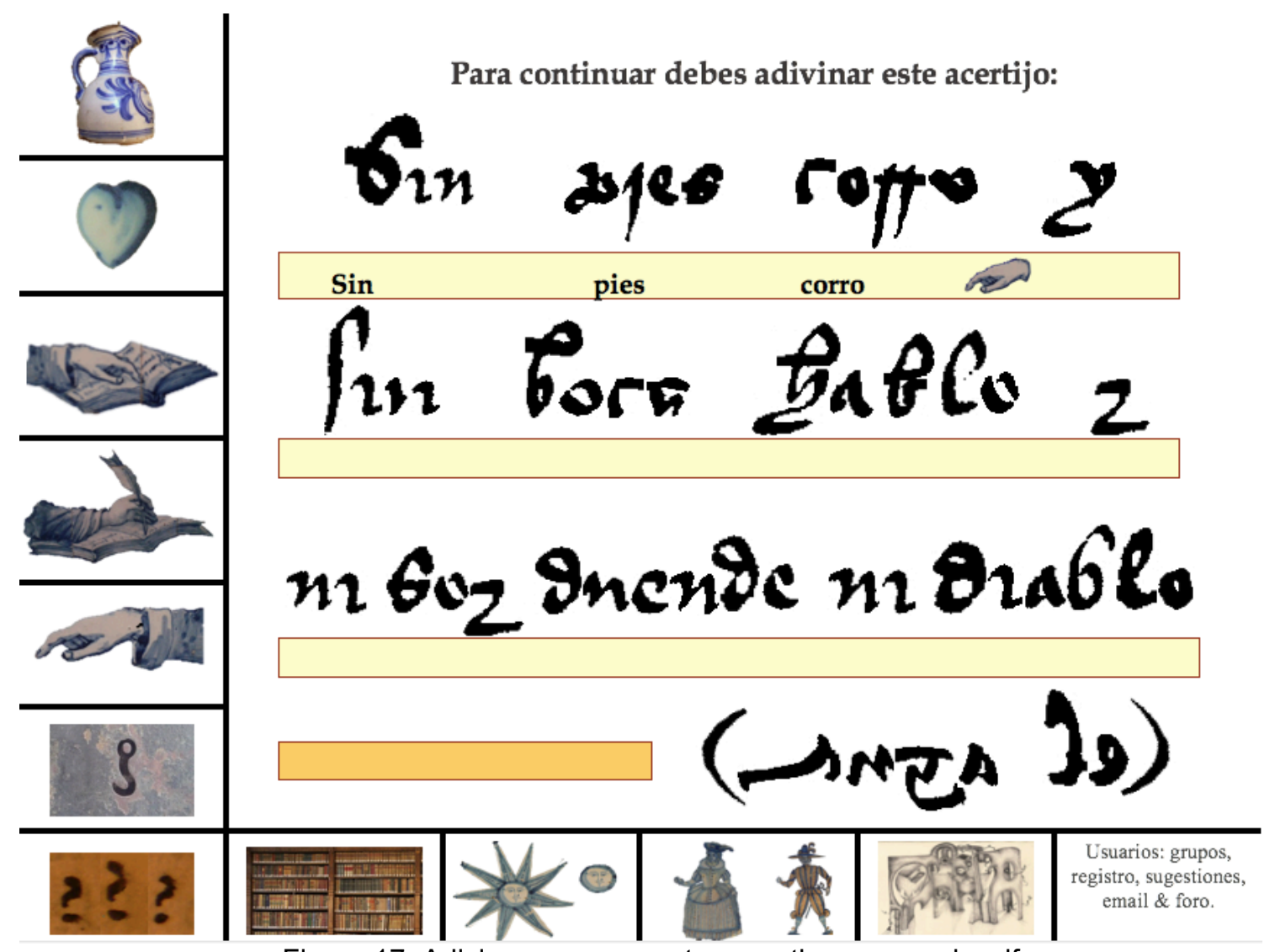

Figura 17. Adivinanza en caracteres antiguos para descifrar.

Ese acertijo viene de un enigma en latín (Currere com pusim, nequeo pede flectere gresum) de los que circulaban en la época. Francisco Santos los tradujo y adaptó del latín al castellano, para mostrar que la segunda lengua permitía expresarse con riqueza y era tan principal como el latín (Santos, 1753: 292). Este hecho facilita además la posibilidad de hacer una versión trilingüe. El enigma del juego en castellano dice: Sin pies corro, y sin boca hablo, y ni soy duende ni Diablo (Figura 17). Se puede cotejar el resultado, o mirar la solución con escritura especular, de caracteres inversos, que dice el agua.

Si aciertas, ganas el primer libro de Francisco Santos que la inquisición censuró (Figura 18), que engrosará la biblioteca. Se titulaba Bello gusto de la moda en material de literatura, o acertada idea del ilustrísimo Feijoo (Santos, 1753). Su portada procede del ejemplar preservado en la Biblioteca Nacional de España (Fondo Antiguo, Signatura 6/6708). 


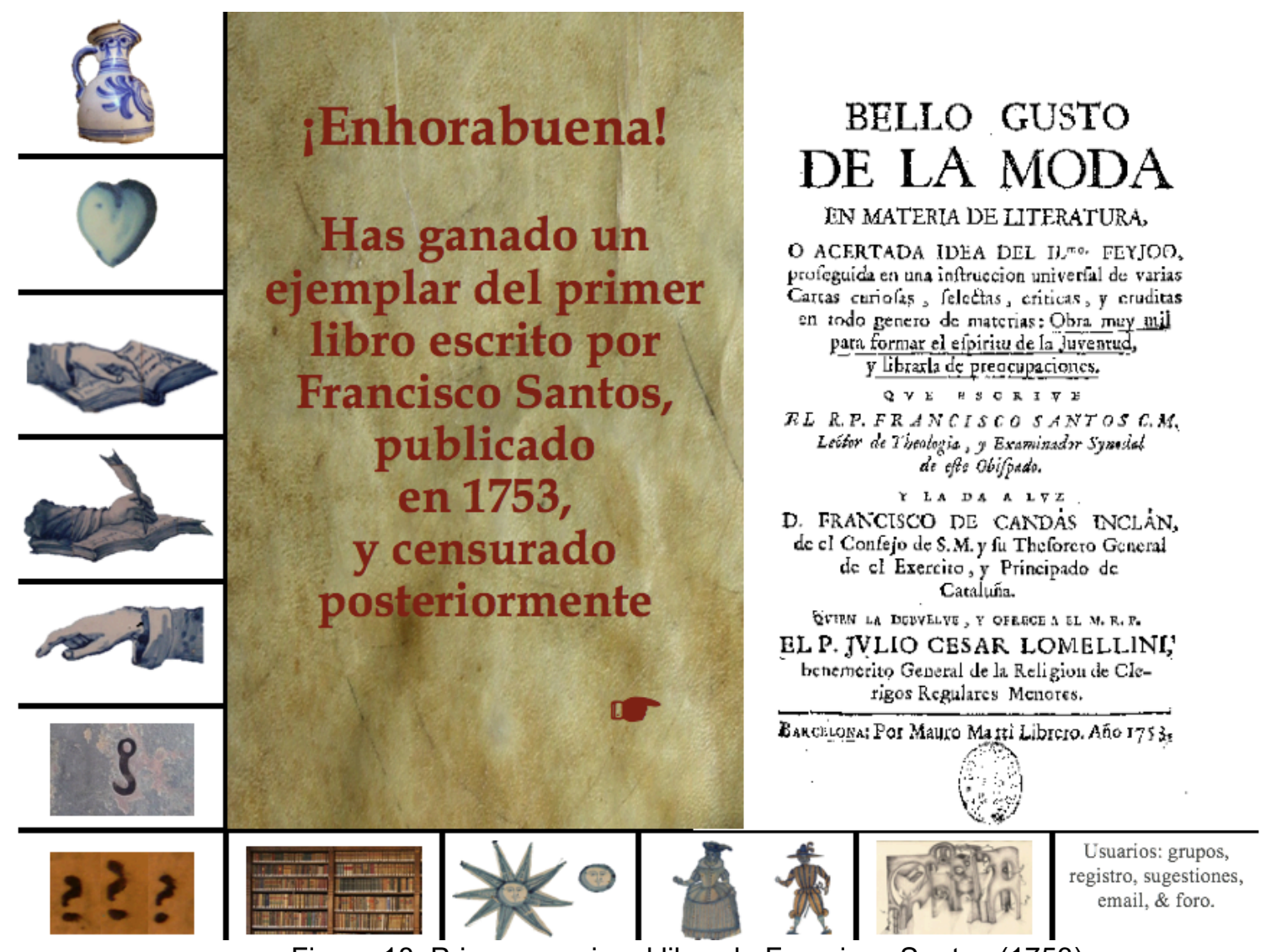

Figura 18. Primer premio, el libro de Francisco Santos (1753).

Resumiendo, el juego consiste en ir superando enigmas de esa y otra naturaleza, para avanzar. Solucionándolos, el usuario será capaz de llegar a un sinfín de espacios, subiendo las escaleras infinitas, traspasando el vano perenne, etc.

\section{CONCLUSIONES}

Los avances interdisciplinares existentes entre las NTIC, en conjunción con la Paleografía y otras ciencias afines, como la Codicología, han rendido resultados innovadores muy provechosos. Sus diversas posibilidades son perceptibles en múltiples campos, que envuelven a las Humanidades Digitales, la Paleografía Digital y los cursos digitales interactivos de Paleografía. Todo ello logra que cada vez sea más normal ver documentos segmentados y coloridos por la web, de apariencia visual atractiva y de libre acceso. Paralelamente, las metodologías lúdicas se han ido introduciendo cada vez más en las técnicas docentes generales, con corrientes innovadoras que incluyen exitosamente juegos educativos en la enseñanza.

Ese contexto tan moderno parece apropiado y preparado para emplear juegos como complemento docente en materias tan eruditas como la paleografía, máxime cuando en diversos países dicha disciplina no suele gozar de gran reputación entre el alumnado, que se 
especializa en ella escasamente, y, como consecuencia, son pocas las asignaturas de la materia en los planes universitarios, que tienden a verse cada vez más reducidas.

Una forma de incentivar a aprender paleografía consiste en incluir juegos en dicha docencia. Sin embargo, existen aún pocos en el panorama internacional digital, como los citados Ducking Stool Game y Early American Handwriting Game. También hay algunos juegos en la Paleoteca, más borradores, como el de Santos, propuesto en este artículo.

Los juegos de Paleografía son escasos si se atiende al apelativo que ofrece la entidad que ha creado el juego. Sin embargo, hay bastantes actividades interactivas de apariencia lúdica para practicar paleografía que reciben diversos apelativos como actividades, ejercicios o tutoriales, pero no juegos. Ello puede deberse varias razones, por ejemplo, a la disparidad de opiniones subjetivas para definir un mismo hecho, más lo endebles que son las fronteras del lenguaje, que complican definir cuándo comienza un juego y cuándo otra acción. Además, cabe plantear si introducir juegos para aprender materias tan serias como la paleografía puede ser una tarea difícil de aceptar por la academia.

En cualquier caso, es provechoso incluir en la docencia los juegos y los ejercicios de paleografía mencionados, por sus múltiples ventajas para hacer competente al alumno en la lectura paleográfica. Ayudan a aprender a identificar grafías antiguas, a desarrollar abreviaturas y, sobre todo, a reforzar conocimientos de la materia adquiridos de forma previa. El esfuerzo intelectual invertido es reducido, basado en el mecanismo de prueba y error que, repitiendo, ayuda a seleccionar y consolidar acciones acertadas, y a rechazar las erradas, de forma consciente e inconsciente. De ese modo, el aprendiz se relaja, convive con los colegas, y resta importancia al hecho de cometer errores.

\section{REFERENCIAS BIBLIOGRÁFICAS}

BELLOTTI, F., BERTA, R., GLORIA, A.D., D'URSI, A. y FIORE, V. (2012). "A Serious Game Model for Cultural Heritage". Journal of Computing and Cultural Heritage, 5.4, 17, 127.

Bellotti, F., KAPRAlos, B., LeE, K., MORENO-GeR, P. y BERTA, R. (2013). "Assessment in and of Serious Games: An Overview". Advances in Human-Computer Interaction, 1-11.

BROOKES, S., STOKES, P.A., WATSON, M., MARQUES DE MATOS, D., (2015). "The DigiPal Project for European Scripts and Decorations". En Writing Europe 500-1450: Texts and Contexts. Essays and Studies, A. Conti, O. Da Rold y P. Shaw (eds.), 68, 25-58. Cambridge: D. S. Brewer. 
CAILLOIS, R (1961). Man, Play, and Games. New York: Free Press of Glencoe.

CARTELLI, A. y PALMA, M. (2009). "Digistylus-An Online Information System for Palaeography Teaching and Research". En Codicology and Palaeography in the Digital Age, 2, F. Fischer, C. Fritze, G. Vogeler (eds.), B. Assmann, M. Rehbein, P. Sahle (colabs.), 123-134. Norderstedt: BoD.

CASTRO CORREA, A. (2014). "Paleografía Latina: recursos para docentes y estudiantes o sobre cómo no perderse en la Red". Espacio, Tiempo y Forma. Serie III. Historia Medieval, 27, 211-228.

CHIN, J., DUKES, R. y GAMSON, W. (2009). "Assessment in Simulation and Gaming. A Review of the Last 40 Years". Simulation and Gaming, 40.4, 553-568.

CIULA, A. (2005). "Digital Palaeography: Using the Digital Representation of Medieval Script to Support Palaeographic Analysis". Digital Medievalist, 1.2, 1-31.

CROOKALL, D. (2010). "Serious Games, Debriefing, and Simulation/Gaming as a Discipline". Simulation and Gaming, 41.6, 898-920.

DETERDING, S., DIXON, D., KHALED, R. y NACKE, L.E. (2011a). "From Game Design Elements to Gamefulness: Defining 'Gamification'”. MindTrek'11. Proceedings of the $15^{\text {th }}$ International Academic MindTrek Conference: Envisioning Future Media Environments, 9-15. Nueva York: ACM.

DETERDING, S., SICART, M., NACKE, L.E., O'HARA, K. y DIXON, D. (2011b). “Gamification: Using Game-Design Elements in Non-Gaming Contexts". Proceedings of $\mathrm{CHI} 2011$, 2425-2428. Vancouver: ACM Press.

ELKONIN, D.B. (1980). Psicología del juego. Madrid: Pablo del Río Editor.

FEIJOO, B.J. (2014). Cartas eruditas y curiosas, I. Edición crítica de I. Urzainqui y E. San José

Vázquez. Oviedo: Instituto Feijoo de Estudios del Siglo XVIII. KRK Ediciones.

FERNÁNDEZ-MOTA, D., LLADÓS, J. y FORNÉS, A. (2014). "A Graph-Based Approach for Segmenting Touching Lines in Historical Handwritten Documents". International Journal on Document Analysis and Recognition, 17.3, 293-312.

FISCHER, F., FRITZE, C. y VOGELER, G. (eds.); ASSMANN, B., REHBEIN, M. y SAHLE, P. (colabs.) (2010). Codicology and Palaeography in the Digital Age, 2. Norderstedt: BoD. FREIRE, M., SERRANO-LAGUNA, Á., IGLESIAS, B.M., MARTíNEZ-ORTíZ, I., MORENOGER, P. y FERNÁNDEZ-MANJÓN, B. (2016). Game Learning Analytics: Learning Analytics for Serious Games, in Learning, Design and Technology, 1-29. Cham: Springer International Publishing.

GLORIA, A.D., BELLOTTI, F., BERTA, R. y LAVAGNINO, E. (2014). "Serious Games for Education and Training". International Journal of Serious Games, 1.1, 1-15.

HASSNER, T., SABLATNIG, R., STUTZMANN, D. y TARTE, S. (eds.) (2014). Digital Palaeography: New Machines and Old Texts [Dagstuhl Reports], 4.7, 112-134. 
HUIZINGA, J. (1980). Homo Ludens, A Study of the Play-element in Culture. Londres: Routledge-Kegan Paul.

LÁZARO CARRETER, F. (1997). El dardo en la palabra. Barcelona: Círculo de Lectores Galaxia Gutenberg.

MALAGÓN, C., RIZKY, R., KIM, Y., MARZAL, F. y IZQUIERDO, L. (2012): "Automatic Abbreviation Detection in Medieval Medical Documents". En ICFHR'12 Proceedings of the International Conference on Frontiers in Handwriting Recognition, 337-342. Washington DC: IEEE Computer Society.

MORENO CASTILLO, R. (2006). Panfleto antipedagógico. Barcelona: El lector universal.

REAL ACADEMIA ESPAÑOLA (2016). Diccionario de la Lengua Española. Edición del Tricentenario. Recuperado de http://dle.rae.es/?w=diccionario el 08/06/2016.

REHBEIN, M., SAHLE, P. y SCHASTAN, T. (eds.); ASSMANN, B., FISCHER, F. y FRITZA, C. (colabs.) (2009). Codicology and Palaeography in the Digital Age. Norderstedt: BoD. RODARI, G (1983). Gramática de la fantasía. Introducción al arte de inventar historias. Barcelona: Argos Vergara.

SÁNCHEZ MAIRENA, A. (2014). "Acercando los archivos a los ciudadanos. Una experiencia desde el Portal de Archivos Españoles (PARES) del Ministerio de Educación, Cultura y Deporte". Arbor, 190.765, 1-21.

SANTOS, F. (1753). Bello gusto de la moda en material de literatura, o acertada idea del ilustrísimo Feijoo, proseguida en una instrucción universal de varias cartas curiosas, selectas, críticas y eruditas en todo género de materias. Obra muy útil para formar el espíritu de la juventud, y librarla de preocupaciones. Barcelona: Mauro Martí.

SCHILLER, J.C.F. (1981). Cartas sobre la educación estética del hombre. Buenos Aires: Aguilar.

SCHUNK, D.H. (2012). Teorías del aprendizaje, una perspectiva educativa. México: Pearson Educación.

STOKES, P. (2008). "Palaeography and Image Processing: Some Solutions and Problems". Digital Medievalist, 3. University of Lethbridge. Recuperado de http://www.digitalmedievalist.org/journal/3/stokes/ el 27/04/2017. (2009). "Computer-Aided Palaeography, Present and Future". En Codicology and Palaeography in the Digital Age, 309-338. Norderstedt: BoD. (2010). "Teaching Manuscripts in the Digital Age". En Codicology and Palaeography in the Digital Age, 2, F. Fischer, C. Fritze y G. Vogeler (eds.); B. Assman, M. Rehbein y P. Sahle (colabs.), 229-425. Norderstedt: BoD.

STUTZMANN, D. (2010). "Paléographie statistique pour décrire, identifier, dater... Normaliser pour coopérer et aller plus loin?". Codicology and Palaeography in the Digital Age, 2, F. Fischer, C. Fritze y G. Vogeler (eds.), B. Assmann, M. Rehbein y P. Sahle (colabs.), 
247-277. Norderstedt: BoD.

VÁZQUEZ DE PARGA, L. (ed. y trad.) (1970). Tractatus de Ludo Scacorum. Madrid: Biblioteca Nacional de España.

WEBBER, T. (2015). "An Introduction to the Project 'Models of Authority: Scottish Charters and the Emergence of Government', 1100-1250". Scripta: An international Journal of Codicology and Palaeography, 8, 177-180.

WOLF, L., POTIKHA, L., DERSHOWITZ, N. (2011). "Computerized Paleography: Tools for Historical Manuscripts". En Proceedings of International Conference on Image Processing (ICIP 2011), 3545-3548. Bruselas: Bélgica.

ZOZAYA-MONTES, L. (2009). "El desarrollo de competencias en Historia y Ciencias y Técnicas Historiográficas a través de un espacio virtual en Internet". Relada (Revista Electrónica de $A D A), 3.3,240-248$.

(2012a). "La aplicación de técnicas informáticas con fines docentes para un manual de paleografía". En La escritura de la memoria. Libros para la administración. IX Jornadas de la Sociedad Española de Ciencias y Técnicas Historiográficas, J.Á. Munita Loinaz y J.A. Lema Pueyo (eds.), 365-370. Vitoria: Universidad del País Vasco.

(2012b). "Difusión de documentación primaria digitalizada como arma de doble filo en la Historia. Un ensayo futurista". MEl, Métodos de Información (Monográfico: Hacia la Globalización de la información), 3.4, 117-125.

(2012-2016). "Recursos digitalizados de libre acceso". En Paleografía y Ciencias afines. Recuperado de https://paleografia.hypotheses.org/on-line-archivos-digitales el 28/04/2017.

(2013-2016). Paleoteca, espacio virtual con juegos de paleografía. Recuperado de http://paleoteca.wordpress.com/ el 28/04/2017.

(2013). "Libros prohibidos: la Inquisición contra la obra del clérigo ilustrado Francisco Santos". En Hacia 1812, desde el siglo ilustrado. Actas del V Congreso Internacional de la Sociedad Española de Estudios del Siglo XVIII, F. Durán López (ed.), 151-166. Gijón: SEESXVIII-Ediciones Trea.

(2014a). "Epiteca: una ludoteca virtual para reforzar conocimientos de epigrafía latina". En VII Jornadas de ludotecas de la comarca de la sierra de Albarracín. Juegos romanos y juegos de agua. Ponencias y comunicaciones, P. J. Lavado Paradinas y V. M. Lacambra Gambau (coords.), 155-170. Albarracín: Perruca Ind. Gráfica. (2014b). "Cursos online de Paleografía. Herencias, limitaciones, logros y propuestas". En El profesional de la información (Monográfico de Humanidades Digitales), 23.5, 475-484. 
(2015a). "Educational Innovation: New Digital Games to Complement the Learning of Palaeography”. En DigiPal V Symposium 2015: The Phantom Minuscule, P. Stokes y S. Brookes (dirs.). Londres: King's College London.

(2015b): "Digital Games for Learning. A Palaeography Project". En EADH Day: European Association for Digital Humanities Symposium. Madrid: LINHD-UNED. Recuperado de http://e-spacio.uned.es/congresosuned/index.php/eadh/EADHDay/paper/view/180 el 28/04/2017. 